\author{
Marién MAdera GonZÁLEZ
}

Departamento de Geografía. Universidad de Oviedo

\title{
La ordenación urbanística del borde occidental de Oviedo. Proyectos y materialización
}

\section{RESUMEN}

Se aborda el proceso de construcción de la fachada de poniente en Oviedo. Se exponen los diferentes proyectos, fallidos o no, que, en cuanto a ordenación para ese sector, han diseñado las distintas generaciones de planes generales vigentes, así como las características específicas de cada propuesta, el contexto histórico en que se producen y la influencia de los ciclos económicos sobre las mismas.

\section{RÉSUMÉ}

Nous abordons ici le processus de construction de la façade occidentale d'Oviedo. Nous exposons les différents projets, réussis ou non, qui, au vu de la réglementation dans ce secteur, ont modelé les différentes générations de plans généraux en vigueur, ainsi que les caractéristiques spécifiques de chaque proposition, le contexte historique au sein duquel elles

\section{INTRODUCCIÓN}

$L$ a construcción de la ciudad no es un fenómeno inmediato, sino un proceso lento que sólo permite comprobar los efectos de las decisiones adoptadas por el planeamiento años más tarde (Leguina, 2004; Ezquiaga, 2011, y López de Lucio, 2011) Para desarrollar esa idea de partida a escala local, puede obtenerse un buen ejemplo siguiendo la evolución de los barrios situados a poniente de la ciudad de Oviedo, recientemente consolidados a pesar de que su ocupación estaba prevista desde hacía décadas. Su escala y su organización relativamente compleja son suficientes como para facilitar la comprensión de un hecho bien sustancial: la articulación de los sucesivos modelos, fallidos o no, que en cada contexto ont été faites et l'influence des cycles économiques sur ces dernières.

\section{Abstract}

Here, we present the building process of the occidental facade of Oviedo. We describe the different projects, successful or not, that, with respect to the rules for this sector, have modelled the different generations of operative General Plans, as well as the specific characteristics of each proposal, the historical context in which they take place and the influence of the economic cycle on them.

\section{Palabras Clave/Mots Clé/Keywords}

Planeamiento urbanístico, urbanismo, crecimiento espacial, Oviedo. La planification urbaine, urbanisme, la croissance spatiale, Oviedo. Urban planning, town planning, spatial growth, Oviedo.

histórico, desde 1957 hasta la actualidad, se propusieron para ordenar el crecimiento urbano, así como las coyunturas económicas, políticas y sociales más favorables para su materialización final.

Con el arranque del siglo xxI, el sector situado al extremo occidental de la ciudad de Oviedo modifica sus usos tradicionales para transformarse, al fin, en un distrito urbano. El paisaje que hoy podemos observar en los desarrollos residenciales de La Florida, Las Campas, incluso parte de La Ería, es fruto de la aplicación, con algunas modificaciones, del Plan General de Ordenación Urbana de 1986 (Tomé, 2001). Las exigencias en cuanto a calidad de vida urbana, espacios verdes públicos, dotaciones culturales, educativas, deportivas y comunitarias, satisfechas sobradamente en estos polígonos, son pro- 


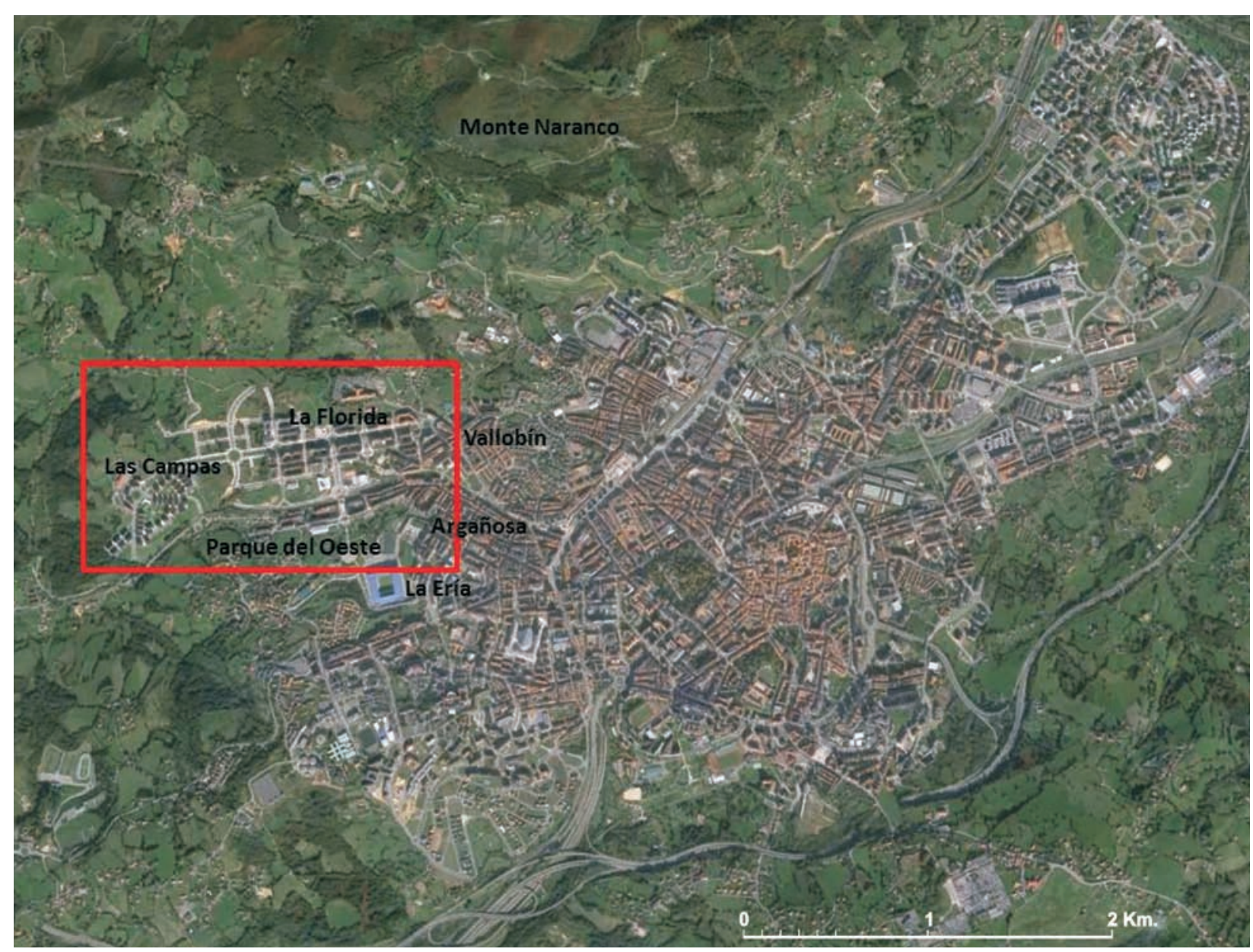

FIG. 1. Oviedo en 2015. En el recuadro, las urbanizaciones de La Florida y Las Campas. Fuente : Google Maps.

ducto de la filosofía que impregna el planeamiento de la democracia, al propugnar un urbanismo más equilibrado desde el punto de vista espacial y social.

Hasta finales de la última década del siglo xx, aquel paraje todavía formaba parte del universo rústico. Era, por tanto, un amplio entorno periurbano con dominante rural (praderías, huertos, caserías, bosques de ribera y pequeñas manchas de bosques mixtos), que sólo en su borde oriental presentaba vestigios de edificación. Sin embargo, su tardía inclusión en la trama urbana no está exenta de proyectos de ordenación sin ejecutar que nos remiten, en su análisis, a una perspectiva temporal que requiere del contexto histórico en que se gestan, pues están sujetos a las tendencias imperantes en los diferentes planes generales de ordenación urbanística que operaron en la ciudad: el de 1957 y el que una década más tarde adoptaba el patrón desarrollista.

\section{EL BOSQUEJO DE LA FLORIDA EN EL PLAN DE 1957}

Al menos en teoría y por lo que respecta a las ciudades españolas, el periodo comprendido entre 1944 y 1953 está muy singularizado urbanísticamente, al comportarse como un laboratorio de ideas y procedimientos preparatorios para la formulación del modelo de planeamiento, las figuras, los instrumentos, el régimen de suelo, los sistemas de actuación y las valoraciones, que alcanzan su máxima definición en la ley sobre Régimen del Suelo y Ordenación Urbana de 1956 (Font, 2011). En la práctica, y desde la misma óptica, los años cincuenta del siglo xx constituyen un periodo confuso y ambiguo, dividido por la aprobación de la LS-56, que no aporta grandes innovaciones técnicas, si bien impone que el planeamiento adopte sus contenidos formales (Terán, 1987). 


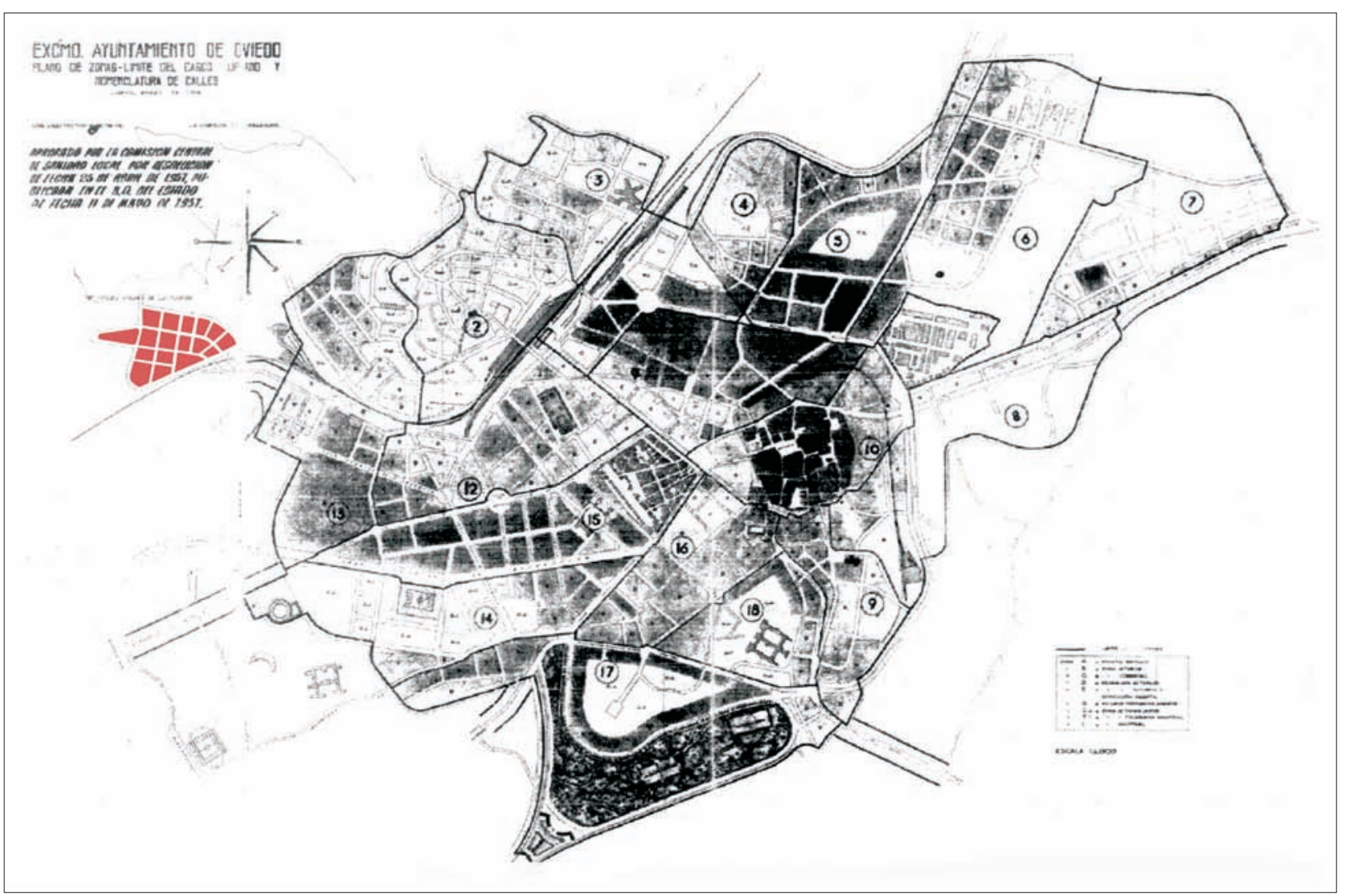

FIG. 2. Su localización, aún fuera del perímetro urbano, no supuso un obstáculo para que en el plan de 1957 La Florida se proyectase como potencial núcleo urbano.

De modo que, salvo excepciones, el urbanismo de esa generación nos remite a simples adaptaciones de documentos anteriores, con las características del planeamiento de extensión o de los confusos planes de urbanización, a los que se añade la zonificación (Terán, 1982). Ése es el caso de Oviedo. Redactado en 1953, antes de entrar en vigor la LS-56, y aprobado en 1957, no deja de ser una adecuación del plan de urbanización de 1941 (Plan Gamazo) a las nuevas circunstancias urbanísticas (Herrán, 2012).

El modelo teórico «racional comprensivo» (Font, 2011) permitía abordar la previsión del futuro crecimiento con una clara definición del perímetro urbano netamente diferenciado del suelo rústico. Se trataba de ordenar el espacio desde la zonificación a través de la tipología de las formas de la edificación (manzana cerrada, bloque abierto, edificación unifamiliar, naves industriales), en esmerada relación con el soporte geográfico y una red viaria en creciente madurez, mostrando su intención «orgánica» con tratamientos diferenciados en unidades independientes, e incorporación de polígonos en la periferia, en consonancia con los paradigmas de la ciudad franquista esbozada por Germán Valentín Gamazo en el mencionado plan (Herrán, 2011).

En su aspecto formal, el PGOu de 1957 agrega al anterior un espacio reducido en lo que respecta a sus límites. Podríamos considerar dicho incremento como remate del borde urbano al integrar las construcciones debidas a parcelaciones particulares. Rectifica y organiza la trama viaria con gran respeto al modelo previo, aunque con una ordenación más ajustada a la realidad de la edificación periférica, dando ordenado cauce a la presión que sobre ese territorio ejercían las clases populares en pleno proceso de inicio del éxodo rural ${ }^{1}$. En el borde occidental, el trazado viario organiza las erías de La Argañosa y Buenavista, urbanizando esos barrios tradicionales con unos criterios que serán asumidos sin apenas alteraciones por el planeamiento desarrollista. La apertura de Valen-

\footnotetext{
El crecimiento demográfico de Oviedo en el intercensal 1050-1960 es de 24.000 habitantes. Fuente INE.
} 


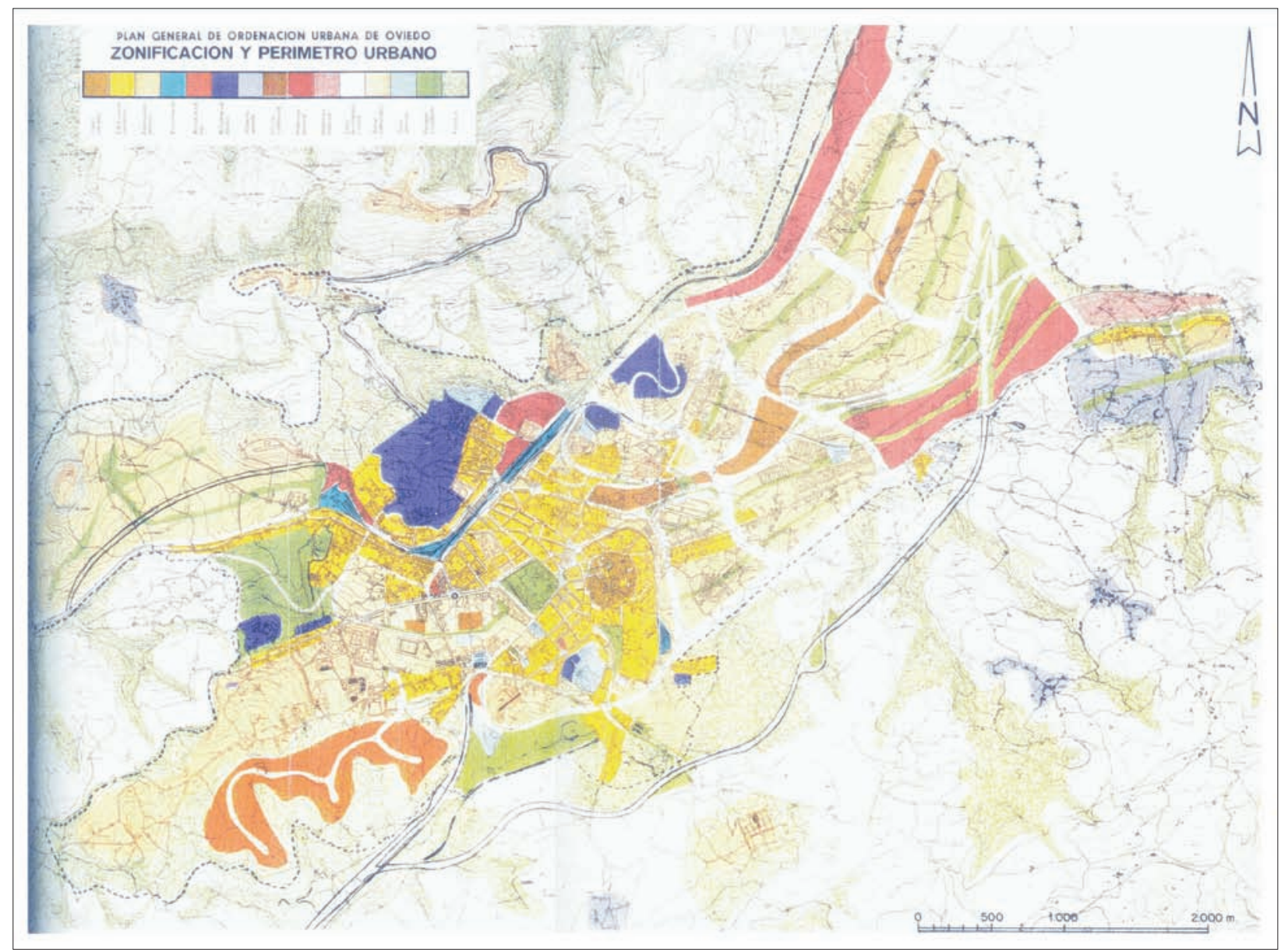

FIGS. 3 y 4. La coincidencia en los límites urbanos previstos en el poou de 1967 (Fig. 3) y el que se aprueba en el último año del siglo xx (Fig.4) pone de manifiesto las grades magnitudes de suelo previsto para urbanizar del primero (plan Mesones), imposibles de gestionar ante la irrupción de un ciclo económico regresivo y una profunda crisis industrial. La quimera del crecimiento ilimitado que irradia el urbanismo desarrollista evidenciará graves problemas estructurales de compleja y lenta resolución. En los albores del siglo xxi, toda vez que Oviedo alcanza los 200.000 habitantes y con una fase económica expansiva, tiende a igualarse tanto el perímetro como la orientación del crecimiento espacial.

tín Masip, denominada en el plano Nueva Avenida de la Argañosa, y las calles que la cortan son buen ejemplo de ello.

Así, inicialmente, La Florida aflora como una pieza extraurbana, concebida como un potencial asentamiento fuera de los límites del perímetro que en el propio plano viene a definirse como «núcleo urbano de La Florida», con una disposición regular de la malla urbana que presupone su posterior integración natural.

La precocidad con que se invoca su condición de suelo de reserva, no impedirá el retraso de cinco décadas en su construcción. Demasiados barrios a medio edificar en el interior del perímetro desaconsejaron acometer urbanizaciones en el exterior del mismo. La renovación interna, por recrecimiento de la masa edificada al susti- tuir inmuebles de planta baja por viviendas con mayor altura, generó un pernicioso efecto de calles corredor, así, alojamientos de escasa calidad acogidos a la protección estatal y bloques cerrados destinados a las clases sociales menos favorecidas, transformaron el espacio periurbano colindante a La Florida y fueron poblando las manzanas vacías de los llamados ensanches existentes y futuros: $\mathrm{La}$ Argañosa, Ciudad Naranco, Vallobín...

No obstante, la exigencia en la recién estrenada legislación (ley del Suelo de 1956) de precisar con más rigor los límites del perímetro urbano obliga en 1957 a una nueva planimetría que, al ampliar los márgenes urbanos, integra definitivamente al mencionado espacio en la trama urbana, sin que esa formulación altere en absoluto lo antedicho. 


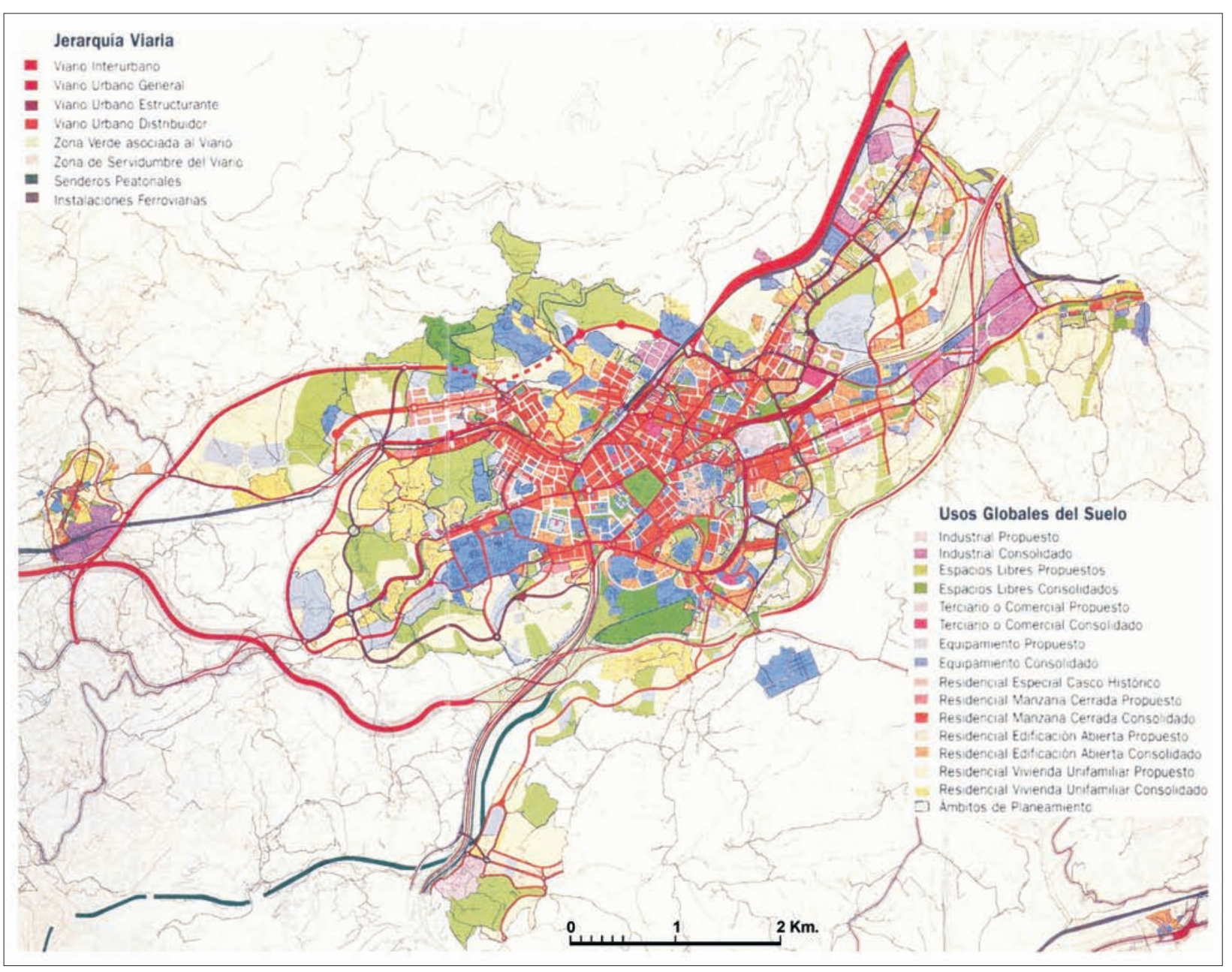

\section{EL MODELO DESARROLLISTA DE JAVIER DE MESONES}

1. Contexto y Filosofía del URBanismo DEl deSARRollo ECONÓMICO (PGOU DE OVIEDO, 1967)

El Plan General de Ordenación del Término Municipal de Oviedo $^{2}$, aprobado definitivamente el 13 de julio de 1967, es la figura de orden superior que regulará el desarrollo urbanístico de la capital asturiana a lo largo de dos décadas.

Durante esa etapa, Oviedo experimenta una modificación sustancial de su naturaleza, registrando un cambio

\footnotetext{
${ }^{2}$ Se inicia en los primeros meses de 1964 y se concluye en Madrid el 27 de agosto de 1965, fecha que coincide con el fallecimiento de Le Corbusier, a cuya memoria se dedica el trabajo: «por ser maestro de maestros y en reconocimiento a los nuevos horizontes que abrió a generaciones de urbanistas».
}

tanto de magnitud (pues la extensión sometida a ordenación sobrepasa las 600 ha) como cualitativo, tratando de orientar su vocación terciaria para centralizar las decisiones. Sin embargo, las previsiones al alza, falazmente fundamentadas en el aumento exponencial de las tasas de natalidad $^{3}$, alimentan la idea de crecimiento ilimitado, en respuesta al cual, el urbanismo de aquel periodo reservó enormes extensiones de terreno para urbanizar que no se verán colmatadas hasta el cambio de siglo. De hecho, los límites marcados en el PGOU de 1999 como ámbito de expansión futura coincidían a grandes rasgos con el que nos ocupa. En 2001, cuando la población alcanza el umbral

\footnotetext{
3 «[...] la ciudad futura está constituida por 31 sectores que oscilan entre los 13.000 y los 25.000 habitantes». Revisión y adaptación del PGOU del término municipal de Oviedo. 1984. Documento de información urbanística, pág 384.
} 


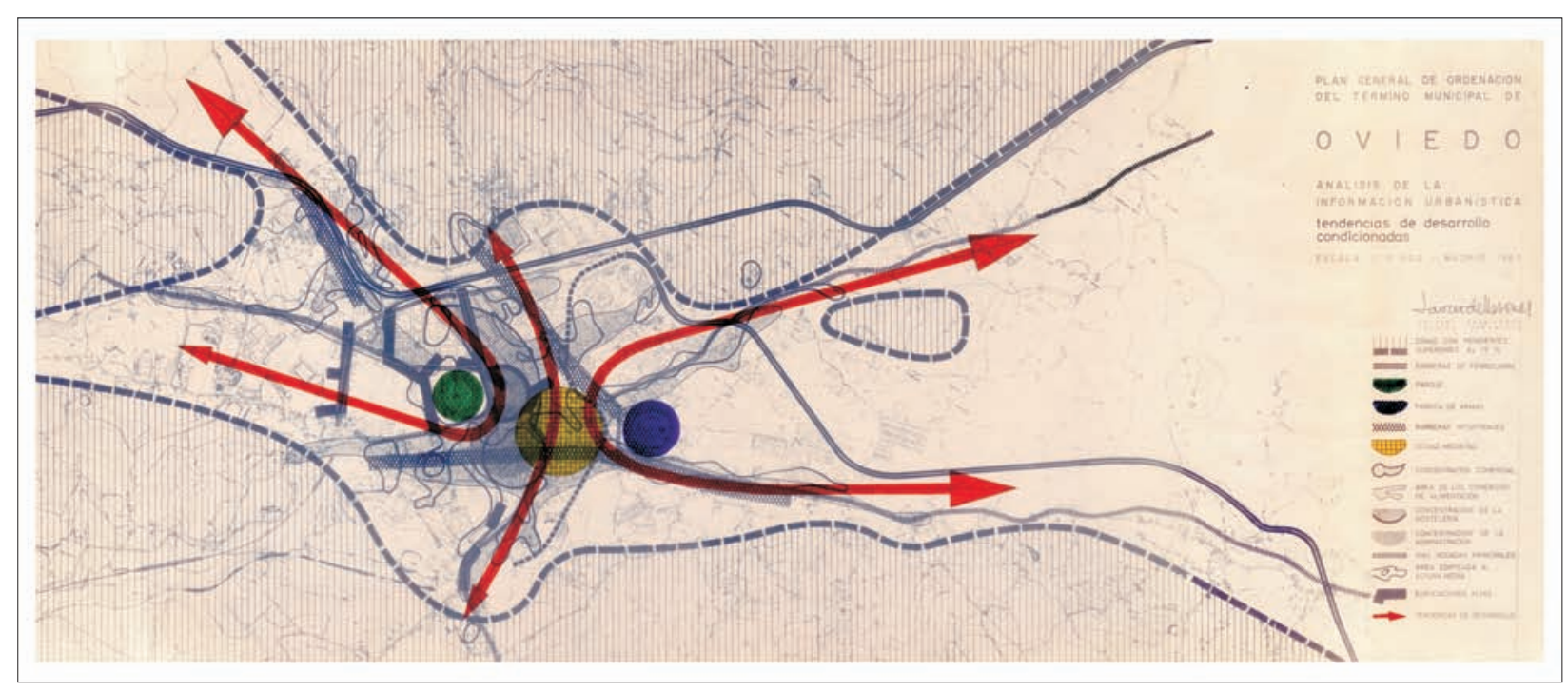

FIg. 5. En la orientación del crecimiento propuesta, Mesones atribuye un importante papel a la topografía al excluir aquellas zonas de la ciudad con pendientes superiores al $15 \%$. Ese criterio, así como la existencia de las piezas hospitalarias de El Cristo y Buenavista, más las instalaciones del cuartel de la Policía Nacional, consideradas por el redactor como tapones que impiden el avance, van a limitar la capacidad urbanística prevista para los mencionados barrios. Se favorece así el impulso nororiental aprovechando la superficie llana del surco prelitoral y la capacidad que le aportan dos importantes vías de comunicación: la antigua carretera de Gijón y la N-634. En sentido opuesto, el nuevo suelo urbano se resuelve con dos grandes polígonos proyectados, La Florida y Montecerrau.

de los 200.000 habitantes $^{4}$, las previsiones de crecimiento demográfico y espacial hechas por Mesones se habrán cumplido, aunque no al ritmo previsto por el urbanista.

Sin embargo, gran parte de las prescripciones del referido plan estaban determinas por el planeamiento anteriormente vigente, que regulaba con precisión a través de sus ordenanzas, las edificaciones existentes y las previstas en el municipio, estableciendo trazados que se encontraban a medio consolidar y fijando nuevos aprovechamientos ${ }^{5}$.

El modelo propuesto por Javier de Mesones y Cabello, doctor arquitecto y técnico urbanista, y su equipo, imagen anticipada de la ciudad que debería materializarse en un periodo de quince años, su fecha horizonte, fue incapaz de dirigir el proceso urbano por los cauces previstos y con la dinámica necesaria. Las razones son tanto locales como de orden general, relativas al proyecto o ajenas a él.

\footnotetext{
${ }^{4}$ Según el INE, en el año 2000 Oviedo alcanza la cifra de 201.154 habitantes.

${ }^{5}$ Revisión y adaptación del PGOU del término municipal de Oviedo. 1984. Documento de información urbanística, pág 383.

${ }^{6}$ Redactan el plan junto a Mesones, doctor arquitecto y técnico urbanista, los también doctores en ingeniería de caminos Rodrigo Baeza y Antonio Valdés; a ellos se suman el economista Ángel Quintana y el abogado Fernando Mola, que componen el equipo redactor.
}

El diseño, deliberadamente direccional y fundamentado en las ideas del Movimiento Moderno, adoptará una concepción urbanística basada en la organización funcional, rompiendo el modelo de ciudad cerrada y compacta para sustituirlo por una estricta separación de las funciones urbanas (habitar, trabajar, circular y cultivar el cuerpo y el espíritu). De modo que la estructura urbana tradicional pierde impulso frente a los nuevos espacios de edificación abierta, rigurosamente sometida a zonificación: residencial, comercial, cultural, industrial, sanitaria, deportiva..., y comunicados entre sí por nuevas infraestructuras viarias que ponen de manifiesto el creciente papel hegemónico de la motorización.

La orientación del crecimiento se ve condicionada tanto por la topografía como por el rol que juegan las piezas hospitalarias de los barrios altos de la ciudad (El Cristo y Buenavista) y las instalaciones del cuartel de la Policía Nacional, que, para el redactor del PGOU, constituyen verdaderos «tapones que impiden su desarrollo» y favorecen la decisión de extender la trama urbana hacia el noreste, dirección lógica al aprovechar parte de la topografía llana del surco prelitoral, así como la capacidad que le aportan dos importantes vías de comunicación: la antigua carretera de Gijón y la N-634, aunque, posteriormente, la construcción de la autopista Y haya interrumpido una de las mismas. En sentido opuesto, dispone dos 
grandes polígonos: Montecerrao al sur y La Florida, a poniente.

El trazado direccional permite conjugar el modelo tradicional de la ciudad ya construida y compacta, que mantendrá regulada mediante edificación intensiva, al que se añade el sector de nuevo crecimiento, el suelo apto para urbanizar, que se despliega en el sentido de los paralelos y constituirá el eje sobre el que aplica tanto la división funcional como la edificación abierta, además de redes viarias mas amplias para canalizar adecuadamente los flujos que impone el ritmo imparable del automóvil.

En ese esquema, que en muchos aspectos servirá como referente a planes posteriores, pese a la sobredimensión espacial sobre la que pretende actuar, se acomoda un conjunto urbano en el que cobran relevancia distintas piezas estructurantes que facilitan la división de funciones: la red arterial, los pasillos verdes y el gran eje cívico comercial que desde General Elorza llega a La Corredoria y que constituye la espina dorsal de lo que será la nueva ciudad, pues vertebra, acentúa y sintetiza la esencia direccional que destila la ciudad teórica (Madera, 1993). Flanqueado por espacios residenciales de edificación abierta, en los que se insertan sendas franjas destinadas a parques y jardines, los mencionados pasillos verdes, que contrarrestan las altas densidades edificatorias, van a erigirse como componente que aportan singularidad en la estructuración y definición de la forma urbana (Tomé y Morales, 2009) y, además, servirán como amortiguadores entre el tejido residencial y la industria que se extiende por ambas márgenes.

Sobre ese patrón urbano se establece «un conjunto de comunidades autosuficientes, según su volumen de población, en el que encuentran satisfacción todas las necesidades» ${ }^{7}$.

Así pues, la fragmentación de la ciudad en unidades jerarquizadas según tamaño y densidad tiene su plasmación en un total de 31 polígonos, de los cuales 17 serían residenciales. Algunos de ellos acabarían fusionándose en su tramitación como planes parciales: Monte Cerrau y El Cristo; Pumarín, Santullano, Teatinos y Rubín; o Ventanielles y Fozaneldi. Ocasionalmente, la fusión de algunos de los previstos facilitará su ejecución durante el periodo de vigencia del PG (el 3 y el 7 al fundirse darán lugar al polígono de Buenavista). Otros, con un evidente escamoteo de dotaciones públicas y espacios verdes, se materializarán parcialmente durante los años setenta (polígono de San Pablo). Sin embargo, una buena parte de

\footnotetext{
Mesones y Cabello (1981, p. 383).
}

los mismos no serán viables en el periodo previsto ni bajo el modelo propuesto.

$\mathrm{Ni}$ siquiera que el autor del plan estructurante se encargase de la mayor parte de los planes para desarrollarlo supuso la garantía necesaria para mantener el carácter global e integrador del plan general. Entre la variedad de razones, una se apunta como suficiente para desbaratar el necesario ensamblaje en la composición jerárquica de las diferentes figuras de planeamiento, consistente en la falta de adaptación de cada polígono o plan parcial a los límites precisos de las propiedades afectadas, problema que se agrava aún más por la multiplicidad de propietarios. Se producen, pues, situaciones complejas, ajenas a la programación temporal del desarrollo espacial por fases, que hubiesen requerido una gestión unitaria y acompasada al proceso de elaboración del plan municipal.

\section{LA FALLIDA PROPUESTA DESARROLLISTA PARA LA} ordenación del poniente. El Plan Parcial del Polígono ResidenCial de La Florida (PP 1), 1969

En 1967, una vez superado el trámite de la aprobación del PGOU de Oviedo por la Comisión Central de Urbanismo, el Ayuntamiento, según lo previsto por la LS-56, anunció concurso nacional para la redacción de diferentes planes parciales que permitiesen su desarrollo. En el caso del polígono de La Florida, el fallo se resolvió a favor de UIASA $^{8}$, que entrega el documento en julio de 1969.

La propuesta, nunca materializada, del equipo de Mesones para ordenar el ámbito de La Florida habría permitido conferir a ese espacio unas características muy diferentes a las actuales, al intervenir sobre una superficie mucho mas amplia (239 ha), con las pautas de crecimiento ilimitado y las expectativas demográficas propias del momento en que se gesta el plan: finales de los años sesenta del siglo $\mathrm{xx}$.

Se corresponde con el polígono número 1 del PGOU del término municipal de Oviedo y se trata de un instrumento de escala intermedia sobre la que el plan tecnocrático pretende actuar ya durante el primer quinquenio ${ }^{9}$, al tener en cuenta «las tendencias del desarrollo urbano espontáneo y la conveniencia de no concretar la actuación

\footnotetext{
${ }^{8}$ UIASA (Urbanismo, Ingeniería, Arquitectura, S. A.) es la empresa que lleva a cabo la redacción de la mayor parte de los planes parciales que permiten el desarrollo del espacio a urbanizar previsto en el PGOU de Oviedo de 1967. A ella pertenece, entre otros, el propio Javier de Mesones y Cabello, el ingeniero Rodrigo Baeza Seco y el letrado Manuel Delgado Iribarren.

9 Plan de Etapas (memoria).
} 
en un solo punto», amparándose en el dudoso beneficio de disponer de abundantes terrenos sujetos a ordenación, lo que, supuestamente, evitaría la especulación.

Y es precisamente la flexibilidad en la dispersión de las actuaciones, la permisividad hacia los agentes del suelo por el incumplimiento de la programación temporal prevista en el Plan de Etapas, además de la enorme superficie sobre la que se pretende intervenir, en desacuerdo con las tasas reales de crecimiento anual, lo que ayuda a entender el fracaso de este proyecto así como el de tantos otros de la misma generación de planes urbanísticos.

\section{A) Delimitación, superficie y estructura}

La superficie destinada al Plan Parcial de La Florida ${ }^{10}$ aumenta con respecto a lo previsto en el Plan General, que le atribuye 150 ha, hasta las ya mencionadas 239 , pues en la redacción del documento que nos ocupa se cree conveniente añadirle espacio destinado a Zona Forestal $\left(415.700 \mathrm{~m}^{2}\right)$, Zona Especial $\left(111.400 \mathrm{~m}^{2}\right)$, Zona Cultural $\left(93.300 \mathrm{~m}^{2}\right)$, además del área prevista como parque del Oeste $\left(204.200 \mathrm{~m}^{2}\right)$, que contabilizan 824.300 $\mathrm{m}^{2}$, algo más de 82 ha que, sumadas a las 150 que el Plan General le otorga a ese sector de futuro crecimiento, se aproximan a dicha cifra.

Situado entre los barrios de Vallobín y La Argañosa, la composición propuesta para La Florida se expandía hasta las proximidades de Las Mazas (en la carretera de San Claudio) bordeando, además, la falda del Naranco. Superaba, por tanto, el conjunto actual de La Florida y Las Campas desbordando ambas e incorporando el sector occidental de La Ería, ya que, al este, el límite coincide con el borde de Alejandro Casona, tramo en que este polígono se yuxtapone al de San Pablo, fragmentando el tradicional barrio de La Argañosa y su ería sin que parezca existir razón objetiva para ello. Incluye, además, el trazado de la línea ferroviaria Oviedo-Trubia, al sur, y los talleres de máquinas de Renfe, en su borde oriental.

Se trata, pues, de un plan parcial integrado por dos unidades de características diferentes: periferia urbana y espacios industriales, frente a un nuevo sector de crecimiento limpio de edificación e inserto en el ámbito rural, aislados entre sí por el enorme desnivel de las Canteras. Dar solución a esa heterogeneidad se solventa, en parte, merced a una adecuada asignación de usos.

Desde el punto de vista formal, la ordenación propuesta por UIASA supondría un brusco cambio del modelo

\footnotetext{
${ }_{10}$ Aprobado en noviembre de 1969
}

tradicional de ciudad compacta, al destinar un amplio porcentaje a la edificación abierta $\left(588.800 \mathrm{~m}^{2}\right)$, tipología edificatoria sobre la que se preveía la edificación de 12.000 viviendas que facilitarían el alojamiento a unas 60.000 o 70.000 personas. Todo ello bajo un diseño que la prensa del momento ${ }^{11}$ califica de «caprichoso rompecabezas» y que los autores definen como organización flexible $^{12}$, en «un intento de huir de la frialdad de las formaciones regulares de bloques uniformes y monótonos» mediante una morfología «atractiva y diferente» en la que predominan los edificios de seis alturas que se alternan, en menor proporción, con torres que alcanzan los diez y seis. $\mathrm{Y}$ aunque en ese esquema de orden abierto, formado por bloques y torres, la distribución de espacios verdes y equipamientos persigue pautas de mayor calidad urbanística, el alejamiento entre las proyecciones demográficas (en las que el plan se sustenta para justificar su sobredimensión espacial) y la realidad resulta abismal, pues el mayor incremento demográfico registrado en la ciudad se produce en los veintiún años que median entre 1960 y 1981 con un saldo de 60.066 habitantes ${ }^{13}$, inferior, por tanto, al total de la población prevista sólo para La Florida.

De modo que esa visión expansionista proyectada por Mesones deja de tener sentido con la irrupción del ciclo económico negativo iniciado a mediados de los setenta, pues entonces comienzan a vislumbrarse los problemas derivados de la enorme superficie a edificar, que se hace más evidente con la brusca reducción de las tasas de natalidad.

No obstante, y prosiguiendo con el análisis del malogrado intento de ordenación, debemos reseñar que para los autores del plan parcial, la estructura urbana proyectada es producto de la organización del viario y de los condicionantes que impone la topografía, así como de las distintas funciones que se le asignan. Su localización periférica y la capacidad de relacionarse con el conjunto urbano serán elementos que contribuyan a determinar su estructura. Por ello, la red arterial está constituida por dos vías en U que se entrelazan, una orientada al sur, que va a permitir la comunicación con la carretera de San Claudio sin que la línea ferroviaria de Feve, que transcurre paralela a la misma, se advirtiese como obstáculo al vislumbrarse su potencial utilización como suburbano para enlazar los desarrollos futuros entre Oviedo y San Claudio.

\footnotetext{
${ }_{11}$ Sanz (1969)

12 Plan Parcial del Polígono Residencial de la Florida (PP 1), 1969. Memoria, 1, p. 15 .

${ }^{13}$ En el intercensal siguiente, 1981-1991, el incremento se verá reducido a 11.578 personas. Fuente: INE.
} 


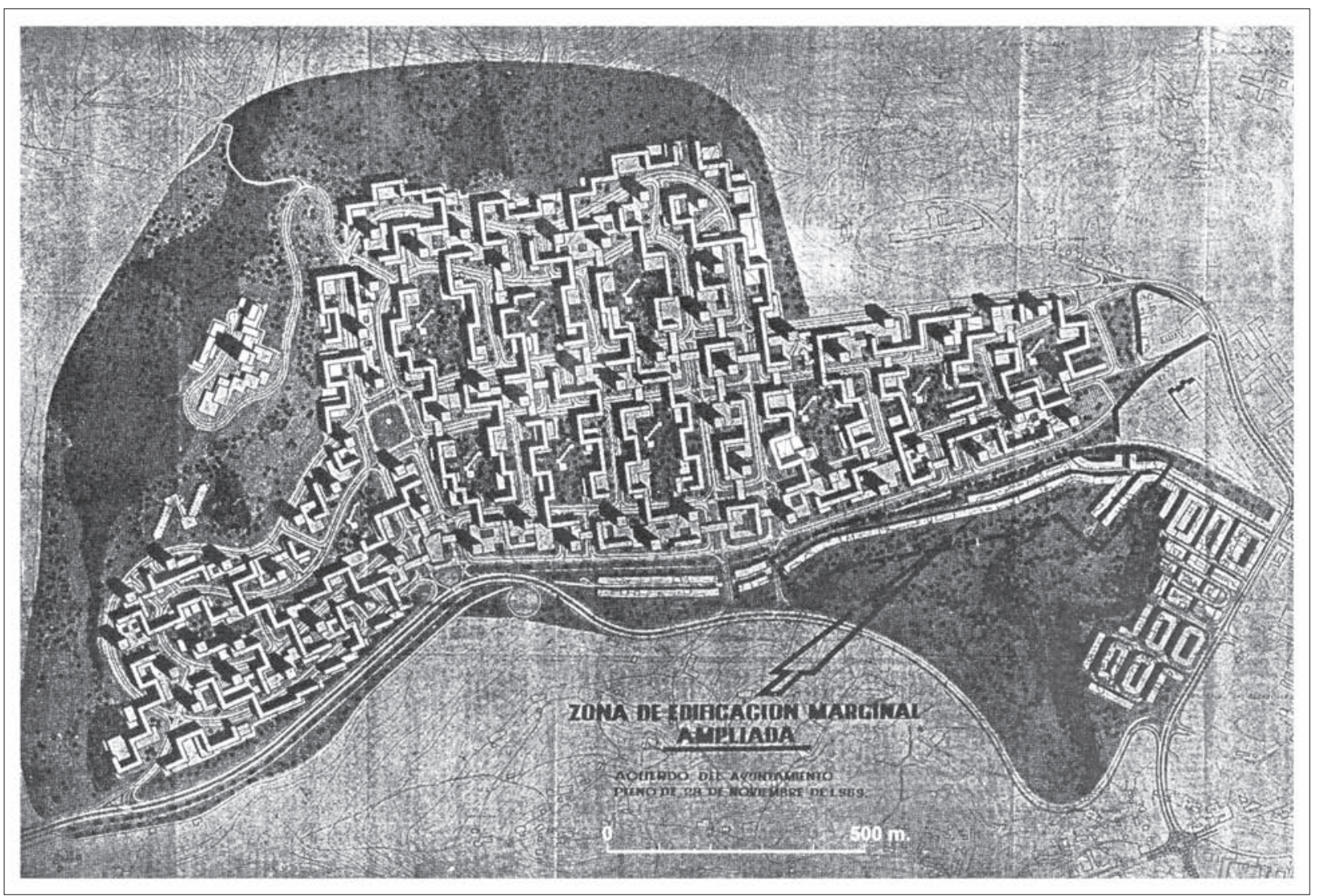

FIG. 6. El frenesí urbanizador desarrollista está presente en la concepción del polígono de La Florida (1969). El proyecto preveía la construcción de 12.000 viviendas que alojasen a 60.000 o 70.000 personas con un esquema edificatorio que la prensa de la época, no sin razón, tilda de caprichoso rompecabezas. Sus expectativas, más utópicas que racionales, se verán arrumbadas por la irrupción de un ciclo económico adverso. Plano de Ordenación General del Plan Parcial de La Florida.

La otra, rumbo al este, facilita la conexión con Vallobín a través de la calle Vázquez de Mella ${ }^{14}$. A su vez, esas arterias se cortan en tramos de longitud más reducida en sentido norte-sur, definiendo unidades menores y facilitando la correcta comunicación interna.

Así pues, sobre ese elemental esquema se vertebra un complejo entramado urbano en el que encuentran acomodo las diferentes usos que alimentan los postulados de la ciudad funcional.

\section{B) La zonificación}

La magnitud del espacio a ordenar y su complejidad estructural harán necesaria una división en dos sectores

\footnotetext{
${ }^{14}$ Plan Parcial de Ordenación del Polígono Residencial de la Florida. Memoria, p. 18
}

más homogéneos para calificarlo, es decir, para asignarle usos. El meridional, al tratarse de periferia urbana, y, por tanto, del espacio de desarrollo en corredor ya construido y en inmediato contacto con la ciudad, se considera preparado para mantener la ordenación tradicional. Por ello se destinará a edificación intensiva que las normas urbanísticas del PG en su capítulo vi definen como «manzana cerrada de edificación alta, con patios interiores, desarrollo a base de calle corredor y alineaciones paralelas al eje de la calle». En el septentrional, prácticamente libre de edificación, el uso predominante (40 \%) será destinado a edificación abierta ${ }^{15}$; y el entorno de los talleres de la compañía de ferrocarriles servirá para revalidar el destino industrial.

\footnotetext{
${ }^{15}$ El capítulo VII de las Normas Urbanísticas vigentes establecían la edificación abierta en zonas residenciales de nueva creación, con edificación de vivienda colectiva en disposición abierta.
} 
La distribución de usos del suelo concebida por UIASA admite la mezcla de funciones «puesto que la fijación de cometidos sobre el pentagrama urbano resulta ser la plasmación de la propia vida cívica, condicionada, tanto por la estructura urbana como por la intuición urbana y comercial de promotores o usuarios» ${ }^{16}$. Dicha distribución es la que sigue:

\begin{tabular}{|lr|}
\hline Superficie delimitada & $2.390 .000 \mathrm{~m}^{2}$ \\
Edificación intensiva & $56.400 \mathrm{~m}^{2}$ \\
Edificación abierta & $588.800 \mathrm{~m}^{2}$ \\
Edificación marginal & $20.700 \mathrm{~m}^{2}$ \\
Zona ferroviaria & $35.200 \mathrm{~m}^{2}$ \\
Tolerancia industrial & $27.200 \mathrm{~m}^{2}$ \\
Zona especial & $30.500 \mathrm{~m}^{2}$ \\
Zona cultural & $93.300 \mathrm{~m}^{2}$ \\
Parques y jardines & $111.400 \mathrm{~m}^{2}$ \\
Zona forestal & $415.700 \mathrm{~m}^{2}$ \\
Viales y protección de viales & $806.500 \mathrm{~m}^{2}$ \\
Parque del oeste & $204.200 \mathrm{~m}^{2}$ \\
Suma & $2.390 .000 \mathrm{~m}^{2}$ \\
\hline
\end{tabular}

De ese desglose, y, puesto que se trata de un polígono residencial, el mayor volumen se destina a los espacios edificables y las redes viarias (viales y protección) que los ordenan, así como el suelo destinado a espacios educativos, necesarios para los habitantes previstos (60.000 personas) precisarían «diez o doce centros de enseñanza Primaria y uno o dos de Secundaria».

La disposición de las funciones previstas sobre la red de infraestructuras será determinante para conformar una imagen atractiva y diferente del nuevo espacio proyectado: bien ordenado, pleno de espacios verdes y abundantes centros educativos, rodeado de una corona forestal y ensamblado a la ciudad construida a través de un gran parque.

Así, sobre un entramado viario resuelto a través de esas dos grandes avenidas entrelazadas, cobra protagonismo el anillo central generado por la intersección de los ejes directores, reservando ese espacio privilegiado para usos cívico comerciales, que a continuación comentaremos. Los tramos de longitud más reducida que seccionan transversalmente esas arterias definen unidades menores

\footnotetext{
${ }^{16}$ Memoria,p. 15.
}

que acogen en su interior usos escolares ${ }^{17}$ y parques y jardines, que, vinculados entre sí, darán lugar a un gran pasillo verde, ya previsto en el PG. El exterior de las citadas unidades menores se reserva para las funciones residenciales y comerciales, alejándose de la estricta separación de usos que caracteriza los modelos urbanos desarrollistas, pues las nuevas tendencias de la sociología urbana se muestran contrarias al concepto de zonificación rígida; así, los autores del plan parcial modifican, mediante los planes de desarrollo, la tendencia, en cuanto a separación funcional, del plan general al que debemos su autoría.

\section{a) Edificación abierta con intensa vida cívica}

De la observación del plano de usos (zonificación) llama la atención, por su nomenclatura y por la amplitud que se destina a ello, lo que se especifica como edificación abierta con intensa vida cívica, término éste que en solitario o acompañado de otro sustantivo (centro cívico, vida cívica) se utiliza profusamente en el planeamiento tecnocrático, posiblemente introducido por las nuevas tendencias de la sociología urbana y, en concreto, por la influencia de Mario Gaviria, que en sus investigaciones trataba de establecer la óptima relación entre la configuración física del espacio y el grado de satisfacción de sus habitantes, proyectando, como resultado de esas investigaciones, lo se denominan «corrientes vitales», es decir, lugares favorecidos por el recorrido mas frecuente, mas proclives a concentrar, dada la atracción que ejercen, edificios o actividades diversas (Terán, 1982). Será, pues, esa intensa vida cívica la que, sobre la edificación abierta, respalde el sistema de calles entrelazadas que solventará la estructura urbana, sobre todo en el anillo central.

En una ciudad que alcanza la primera década de la segunda mitad del siglo xx únicamente con el céntrico parque de San Francisco (9 ha) y el diminuto Campillín (Tomé y Morales, 2009, y Fernández, 2014), llama la atención el espacio dedicado en este proyecto a espacios verdes, ya que, si contabilizamos la zona forestal $\left(415.700 \mathrm{~m}^{2}\right)$ y el parque del Oeste $\left(204.200 \mathrm{~m}^{2}\right)$, pues del corredor verde lineal no existen cifras, nos encontramos ante un proyecto urbanístico novedoso, un modelo urbano que pretende emular patrones exteriores anticipándose a lo que el planeamiento posterior considerará como valores irrenunciables de calidad de vida urbana.

\footnotetext{
${ }_{17}$ Se destinan a estos fines diez escuelas de enseñanza primaria y un gran centro de enseñanza secundaria, situado en el extremo occidental, bajo la zona definida como «especial».
} 


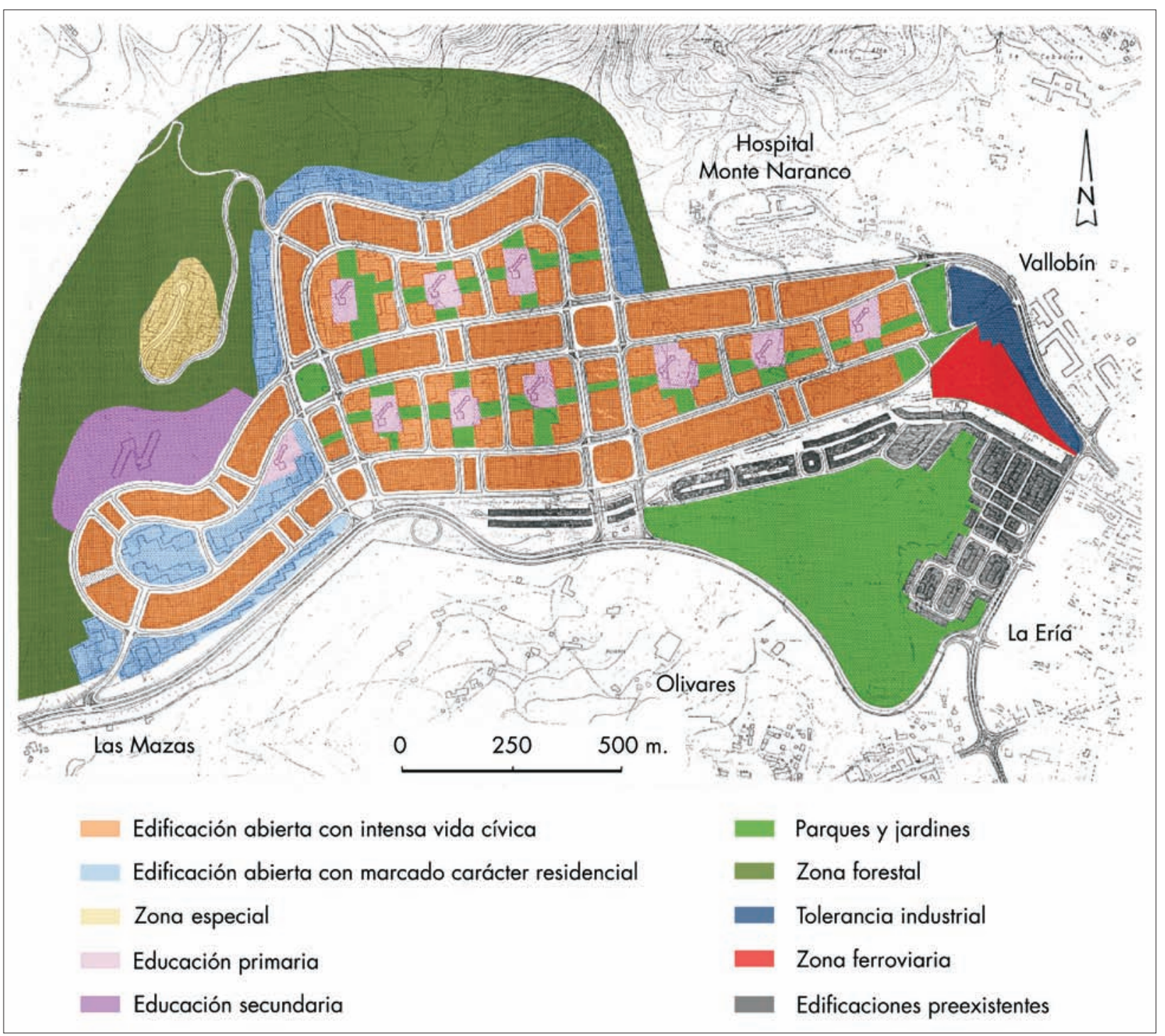

Fig. 7. Plano de usos del suelo del proyecto del Plan Parcial de La Florida (1969). La magnitud del espacio a ordenar (239 ha) y su complejidad estructural contribuirán a la elaboración de un proyecto quimérico, cuajado de buenas intenciones, aunque no exento de oficio. La disposición de la red arterial da lugar a una ordenación urbanística donde las distintas funciones están bien representadas gracias al correcto entrelazado de los espacios verdes, a los numerosos equipamientos, al desahogo proporcionado por la corona forestal y al ensamblaje que el parque aporta en la fusión con la ciudad ya construida.

\section{b) La zona forestal}

La zona forestal, amplia corona que, desde las proximidades del sanatorio antituberculoso del $\mathrm{Na}$ ranco, asciende por la ladera del monte homónimo y se ciñe al borde septentrional hasta el extremo mas oriental del plan parcial, constituye la masa arbórea deseable para proporcionar la carga de oxígeno adecuada, separando, por ese medio, el espacio urbanizado del que le corresponde al monte. En ese sentido, podría ser un tributo a Arturo Soria y Mata, pues en el diseño de la Ciudad Lineal está presente una franja forestal con idénticos fines.

c) El parque del Oeste

En cuanto al parque del Oeste, y aunque no se menciona en ninguno de los documentos consultados, pode- 
FIg. 8. En sus confines meridionales, el parque del Oeste aprovecha el escarpe de la cantera histórica mediante la restauración bien resuelta de la cubierta vegetal. La imagen facilita

la comprensión de la conversión de la antigua cantera en un parque urbano al eliminar definitivamente

la barrera física que dificultaba la correcta vertebración entre barrios, separados por cotas de diferente altitud. Sobre el talud la urbanización de baja densidad de Olivares, a la derecha las instalaciones deportivas del nuevo Carlos Tartiere. Fotografía: M. Madera.

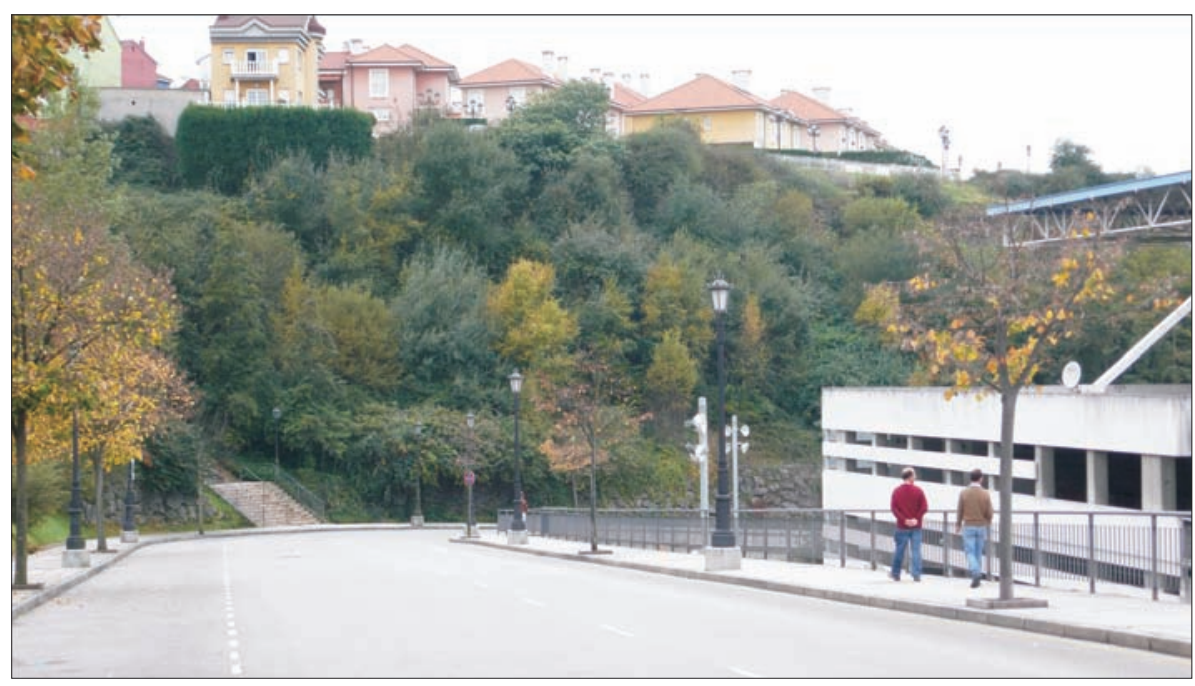

mos considerar que su mera formulación denota el oficio de Mesones al proponer un modelo de ciudad integral, con la lógica de continuidad y comunicación entre todas sus partes (al menos sobre el papel), así como un reparto equilibrado de zonas verdes y equipamientos, de los que, desgraciadamente, apenas algunos vieron la luz. Afortunadamente, esa propuesta será revisada y asimilada por el PGOU de 1986, que decide definir ese espacio como «sistema general»; de ese modo, se generan los mecanismos urbanísticos que facilitarán su definitiva materialización a través de los excesos de aprovechamiento medio del plan parcial al que pertenece como unidad reparcelaria ${ }^{18}$. El planeamiento de la democracia considera que el parque va mas allá de constituir un espacio destinado al ocio y recreo de los residentes en sus inmediaciones. Con la perspectiva actual (también en el fallido plan) constituye un excelente ejemplo de vertebración urbana del polígono con el resto de la ciudad, sobre todo teniendo en cuenta la naturaleza del espacio sobre el que se inscribe: una cantera de 10 ha, cuyo talud (15 m de altura) supuso una evidente barrera física que tradicionalmente impedía la comunicación entre La Argañosa, La Ería y los barrios mas deprimidos de La Fuente de la Plata y La Florida.

La cantera, denominada de Lavapiés ${ }^{19}$, de la que se extrajo piedra durante quinientos años, desarrollaba su extensión desde Olivares y La Gruta (salida a Galicia)

\footnotetext{
18 El plan de 1986 obliga al pp de La Florida a ceder, mediante el mecanismo mencionado, $204.520 \mathrm{~m}^{2}$ para el parque del Oeste. Memoria de gestión, p. 36.

${ }_{19}$ Pando, Luque y Claverol (2011).
}

hasta La Fuente de la Plata y Lavapiés (lo que hoy es Pórticos I), con un prominente desnivel que desde la calle Bances Candamo ascendía por La Ería hasta el entronque de Alejandro Casona con Fuertes Acevedo, en las proximidades del estadio Carlos Tartiere.

La prolongada actividad humana, cinco siglos de extracción de piedra para la construcción de algunos de los edificios mas emblemáticos de la capital del Principado ${ }^{20}$, había dado lugar a un obstáculo difícil de salvar. Así que el diseño del parque del Oeste no sólo soluciona un problema clinométrico, componiendo una zona de disfrute colectivo sobre los terrenos de una cantera histórica, pues explota las posibilidades que ofrecen las distintas cotas de altitud que el beneficio de materiales desde el siglo $\mathrm{XV}$ ha labrado, sino que contribuye a dar respuesta al restablecimiento o a la restauración de la cubierta vegetal para mejorar la calidad ambiental. Mas aún, constituye un innegable nexo de unión urbano.

\section{d) La zona especial}

En el PGOU que inspira este plan parcial, se definen como especiales aquellas áreas que por la singularidad de sus características puedan dedicarse a la práctica del deporte, uso sanitario, universitario, turístico e incluso militar. Actividades, por tanto, que o bien requerían ser localizados en el borde de la ciudad por ser incompati-

\footnotetext{
${ }^{20}$ Parte de la catedral, la capilla de la Magdalena, los palacios del Conde de Toreno, del Duque del Parque, la Casa de Comedias (hoy Biblioteca Pérez de Ayala), la fuente del Fontán y el acueducto de Los Pilares, entre otras edificaciones singulares (Pando, Luque y Claverol, 2011)
} 
bles con los usos residenciales o por precisar grandes extensiones de terreno para su desarrollo. En este caso, circunscrita a la colina de Pando, y dedicada a esparcimiento en general, llegó a barajarse la posibilidad de construir un parque de atracciones (La Nueva España, 30 de noviembre de 1969), así como instalaciones hosteleras, proyectos que no llegarán a materializarse por las razones antedichas.

\section{EL PLANEAMIENTO DE LA DEMOCRACIA Y SU CONTEXTO SOCIOECONÓMICO}

Las dificultades económicas de la segunda mitad de los años setenta, derivadas del aumento de los precios del crudo, así como el desplome de las tasas de natalidad, colocaron el punto final a la quimera de crecimiento ilimitado. Así, la lógica de mercado, siempre conservadora, actuó sobre los espacios centrales y desatendió a la periferia. También permitió el abandono de la ciudad preindustrial, que amenazaba ruina, y la destrucción de la ciudad decimonónica (Tomé, 1988). Ese fenómeno, presente en la mayor parte de las ciudades españolas, al que se une, tras ser promulgada la Constitución de 1978, la asunción de competencias en materia de urbanismo por parte de las comunidades autónomas, y la irrupción de los nuevos ayuntamientos democráticos, propició la reformulación de la ciudad. En ese contexto cobrará un mayor protagonismo la participación vecinal, muy presente en la exploración de otras perspectivas urbanas que contemplasen el equitativo reparto de los equipamientos, la calidad de vida y la integración, mediante sutura, de las distintas piezas de la ciudad.

La evidencia de los problemas mencionados desarrolló una conciencia ciudadana que, capitalizada por los movimientos políticos, canalizó el malestar de los barrios hacia las asociaciones vecinales para reivindicar un urbanismo que atendiese por igual a todas las partes de la ciudad. Es un periodo muy marcado por la cultura democrática municipal, legitimando lo que Jordi Borja (2004) define como «urbanismo ciudadano». En este contexto, aparece una generación de planes que coinciden con el periodo de la Transición y perdurarán durante la década siguiente. Son los que Campos Venuti define como «planes de la ciudad justa», ya que tratan de enmendar las deficiencias, equilibrar las diferencias y distribuir con equidad el suelo público. Todo ello alumbró la etapa mas brillante del planeamiento urbanístico español; así al menos se ha reconocido internacionalmente (Font, 2011).
1. El Plan General de Ordenación Urbana de 1986 o plan de uRgencia de Carlos de la Guardia

Con respecto al urbanismo anterior, el PGOU de 1986 supuso para Oviedo un cambio de ritmo, de escala y de contexto (Montaner, 2004). Podemos definirlo como un plan de urgencia, ya que fue redactado en sólo nueve meses por un equipo multidisciplinar ${ }^{21}$ bajo la dirección del urbanista madrileño Carlos de la Guardia, profesor de la Escuela de Arquitectura de Valladolid. La premura trataba de enmendar la parálisis urbanística que ocasionó la revisión del plan de 1967, llevada a cabo por el propio Mesones en 1981 y aprobada en 1984, pues la reducción de la edificabilidad conforme a los criterios impuestos por la crisis económica y por el aprendizaje sobre nuevos modos de hacer ciudad, demandado por teóricos y ciudadanos, no parecía hacer mella en los agentes inmobiliarios; éstos continuaban empeñados en perpetuar su presión sobre el suelo, ante la debilidad del poder municipal para anteponer los intereses colectivos a los individuales (Tomé, 2001).

Como otros planes coetáneos, calificados por Antonio Font como cautelares o remediales, «a la defensiva en relación a los intereses inmobiliarios», su objetivo radicaba en solucionar los graves problemas ocasionados por la deficiente gestión del urbanismo desarrollista y su propensión a sobredimensionar el espacio correspondiente a las necesidades de urbanización, menguadas ahora por la irrupción de un ciclo económico regresivo y el trasfondo de una profunda crisis industrial. Los inconvenientes de la práctica urbanística del tardofranquismo, evidentes en las ciudades españolas, afectaban estructuralmente, con mayor o menor intensidad, a todas sus partes: a la ciudad preindustrial, sobre la que se cernía la amenaza de ruina de sus edificios ante la desprotección legal, y cada vez mas ocupada por actividades marginales; a la ciudad decimonónica, cuya sistemática destrucción nos privará de un irrecuperable patrimonio arquitectónico, y a la ciudad construida, que había superado las alturas admisibles en la edificación ante la actitud

\footnotetext{
${ }^{21}$ El coordinador del equipo redactor era Pedro Blanco, concejal del Ayuntamiento de Oviedo y arquitecto. El arquitecto gijonés Javier Fombella capitaneaba un grupo joven y comprometido con la búsqueda del equilibrio territorial, la calidad de vida urbana y el equitativo reparto de espacios públicos y equipamientos: los también arquitectos José Manuel Caicoya, Juan Fernández Moriyón y César Fernández Cuevas se encargarían respectivamente del diseño urbano, el medio rural y el Plan Especial de Reforma Interior del Casco Histórico. De los aspectos relacionados con el análisis y diagnóstico del medio urbano, así como de los estudios demográficos se encargó la geógrafa Marién Madera.
} 


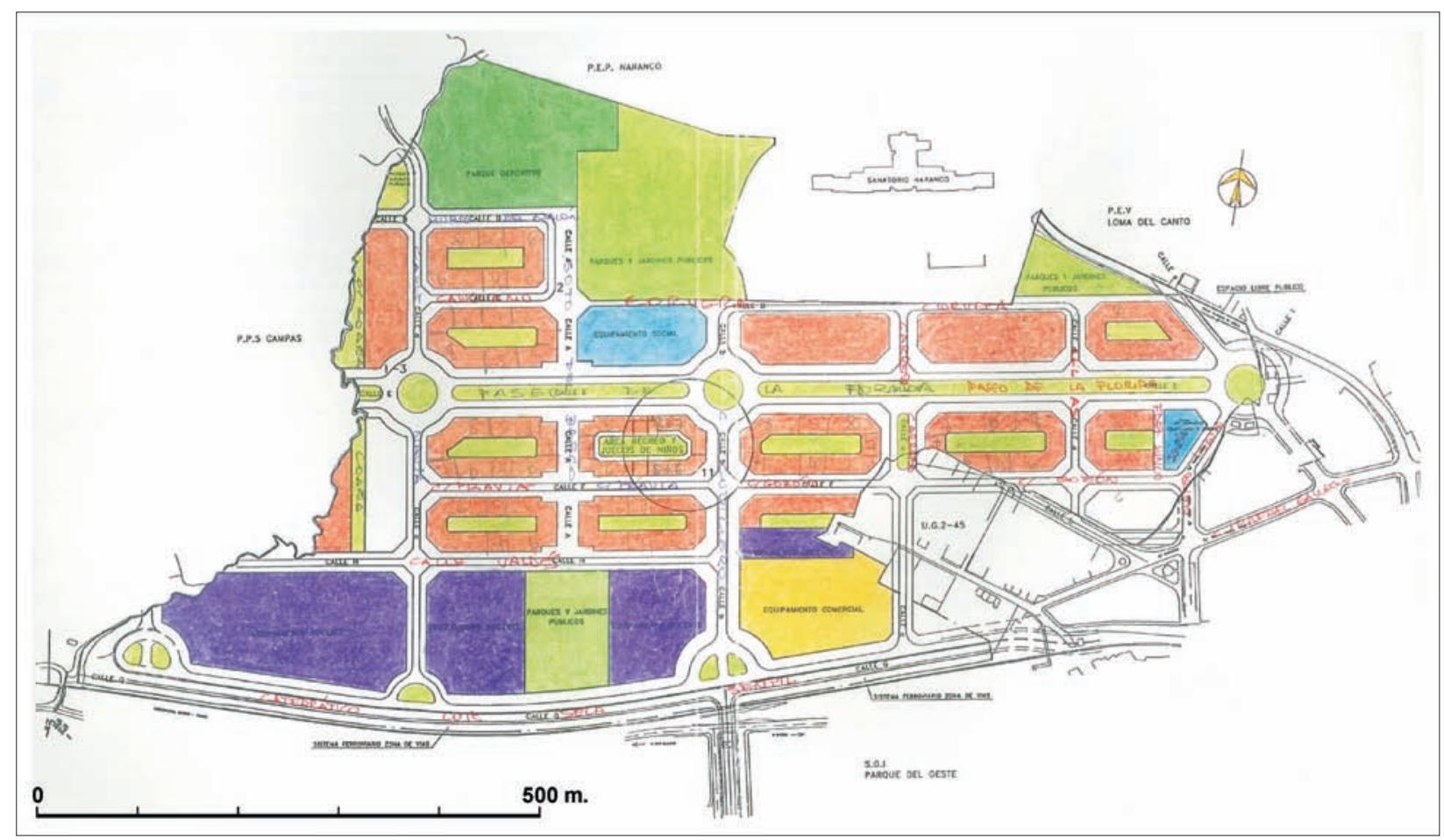

FIG. 9. Esquema de ordenación y usos de La Florida con la unidad de gestión 2-45.

permisiva de técnicos y políticos al identificarlo con la modernidad y el progreso.

La desigualdad entre centro y periferia era patente, pues la presión demográfica, consecuencia del éxodo rural, favoreció el crecimiento caótico y desarticulado de los barrios, lo que conocemos como desurbanización de la periferia (Trapero, 1994). Con barrios enteros carentes de los equipamientos más elementales, que utilizaban los descampados como zonas de juegos (Leguina, 2004), con calles sin pavimentar y deficientemente iluminadas, además de mal comunicados por un rudimentario sistema de transporte público (Madera, 2013).

El patrón a seguir, tras el diagnóstico inicial, se basa en la adopción de decisiones encaminadas a resolver a corto y medio plazo la transformación del tejido urbano, eliminando las trabas impuestas por la segregación espacial que hacía de Oviedo una localidad deficientemente vertebrada, fraccionada por elementos de la infraestructura viaria y ferroviaria (Madera y Tomé, 1996), pues la compleja estructura de la ciudad requiere el ensamblaje correcto de todas sus piezas. Se concedió preferencia a la ocupación de los vacíos intersticiales, contrarios a la idea de habitabilidad y calidad de vida, de ahí la voluntad de «coser» el deshilachado tejido, de tratar las «malformaciones» ${ }^{22}$ y regenerar espacios recuperándolos para la ciudadanía. El equitativo reparto de espacios verdes públicos y equipamientos, tan deficitarios hasta entonces, constituyó otra de las líneas prioritarias de actuación, conscientes tanto de su necesidad, como de su poder transformador del entorno urbano. También se trató de preservar las señas de identidad mediante la recuperación del patrimonio cultural con la figura de planeamiento adecuada, en este caso el Plan Especial de Protección del Casco Histórico.

\section{LA ORDENACIÓN DE LA FLORIDA EN EL URBANISMO DE LA DEMOCRACIA}

Si el objetivo, pues, del PGOU de 1986 era completar la ciudad existente y preparar su desarrollo futuro, parece lógico tener presente a La Florida como posible área de extensión, favoreciendo un asentamiento residencial, previsto ya en anteriores documentos de planeamiento, que permitiese reforzar la imagen de la urbe insertando

\footnotetext{
${ }^{22}$ PGou (1986). Documento de diagnóstico. Ejemplar mecanografiado.
} 


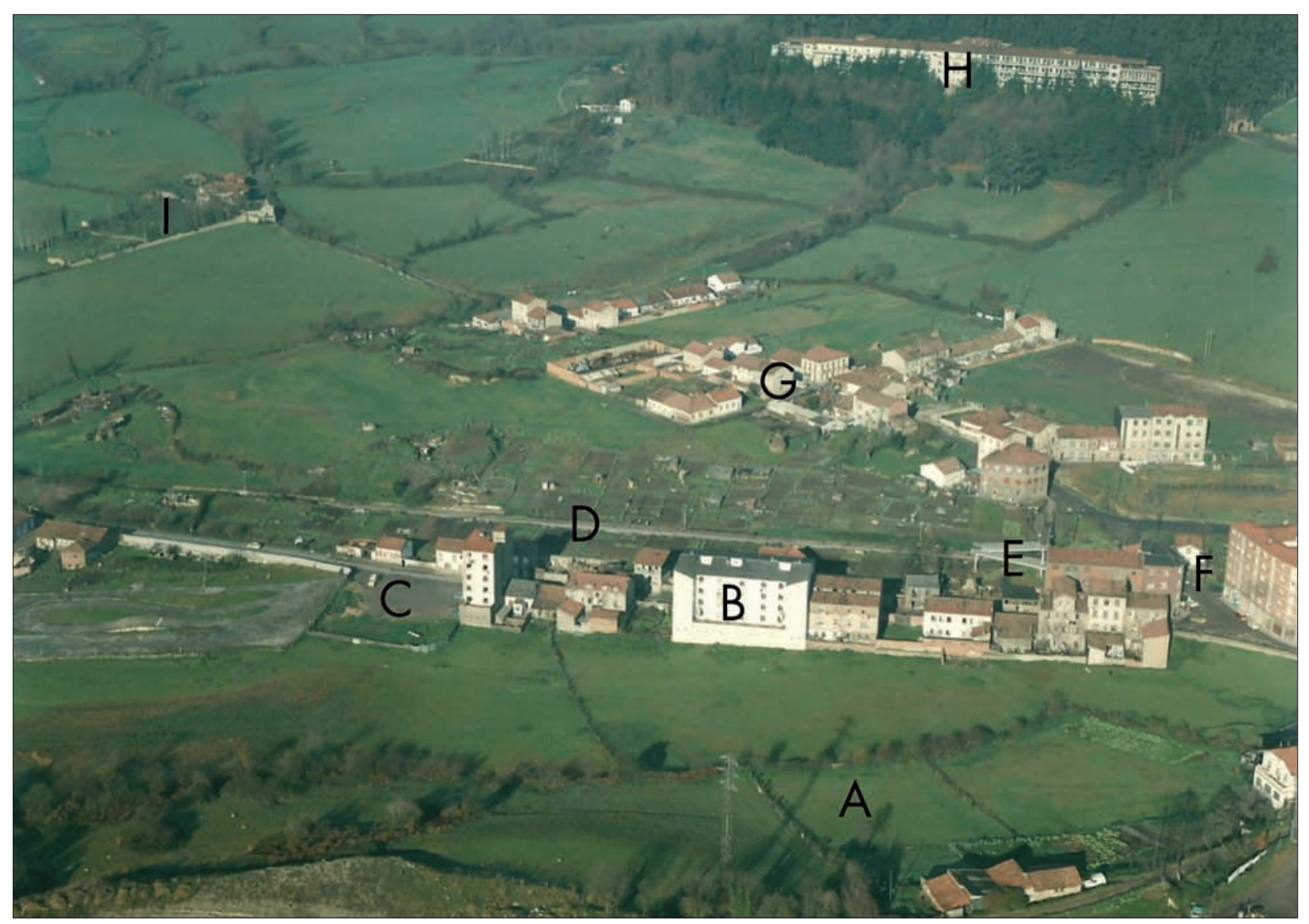

Fig. 10. Aspecto de la Florida a finales de los años ochenta del siglo xx. A) suave vertiente correspondiente al barrio de la Argañosa, donde ahora se encuentra el sector oriental del parque del Oeste. B) Lavapiés, con el caserío previo al ahora ocupado por la urbanización Pórticos I. C) Solares que coinciden con el final del trayecto del autobús urbano San Lázaro-Lavapiés (antigua Línea 5). D) Línea del ferrocarril Oviedo-Trubia. E) Pasarela sobre el trazado ferroviario de Feve que posee allí un apeadero al tiempo que facilita la conexión a pie entre La Argañosa y La Florida. F) Tradicional paso a nivel, senda obligada para acceder al barrio originario de la Florida. G) Núcleo de la Florida tradicional. H) Hospital Monte Naranco. Antes de ser integrado en la red sanitaria pública asturiana, era un sanatorio antituberculoso. I) Quinta Méndez. Una quinta de recreo que, tras la Desamortización, había levantado la familia Méndez Vigo sobre terrenos de la antigua malatería de San Lázaro de Paniceres; de donde proviene el topónimo y que empieza a demolerse al compás de la nueva edificación.

esa nueva pieza en los barrios existentes o futuros a través de una retícula integradora. En consonancia con esos presupuestos, se clasifica ese suelo como urbanizable programado, a desarrollar en el primer cuatrienio con la misma numeración que le había otorgado el planeamiento anterior: plan parcial número 1, La Florida.

Sus características físicas y su situación relativa ratificarán la conversión de ese espacio $\left(406.317 \mathrm{~m}^{2}\right)$ en urbano, a pesar de su carácter periférico y de las deficientes infraestructuras de comunicación existentes ${ }^{23}$, previas

\footnotetext{
${ }^{23}$ La conexión tenía lugar a través de la carretera de Oviedo a Brañes, atravesando previamente el núcleo primitivo de La Florida, que viene a coincidir con
}

a la formulación del PP. La densificación de su entorno con las promociones de Pórticos 1, en la calle Favila y la segunda fase en Vallobín; la integración, en la primera mitad de los años ochenta, del Hospital Monte Naranco dentro la red pública sanitaria ${ }^{24}$, eliminando el rechazo que provocaba su función anterior como sanatorio antituberculoso, y el hallarse potencialmente entre dos parques (el del Oeste, refrendado por el nuevo documento, y el de Purificación Tomás, fruto de un convenio entre el Ayun-

la unidad de gestión de los Reyes (Ug 2-45). Plan parcial número 1 La Florida. Junta de Promotores. Información Urbanística, p. 6. (1994), Ayuntamiento de Oviedo.

${ }^{24}$ Decreto 94/86 de 26 de junio 1986. BOPAP, núm. 215. 
FIG. 11. Inaugurado en 2015, el puente que facilita la conexión entre La Florida y el parque del Oeste elimina, al sobrevolarla, la barrera que siempre supuso el trazado del ferrocarril de vía estrecha (Oviedo-Trubia). Fotografía: M. Madera.

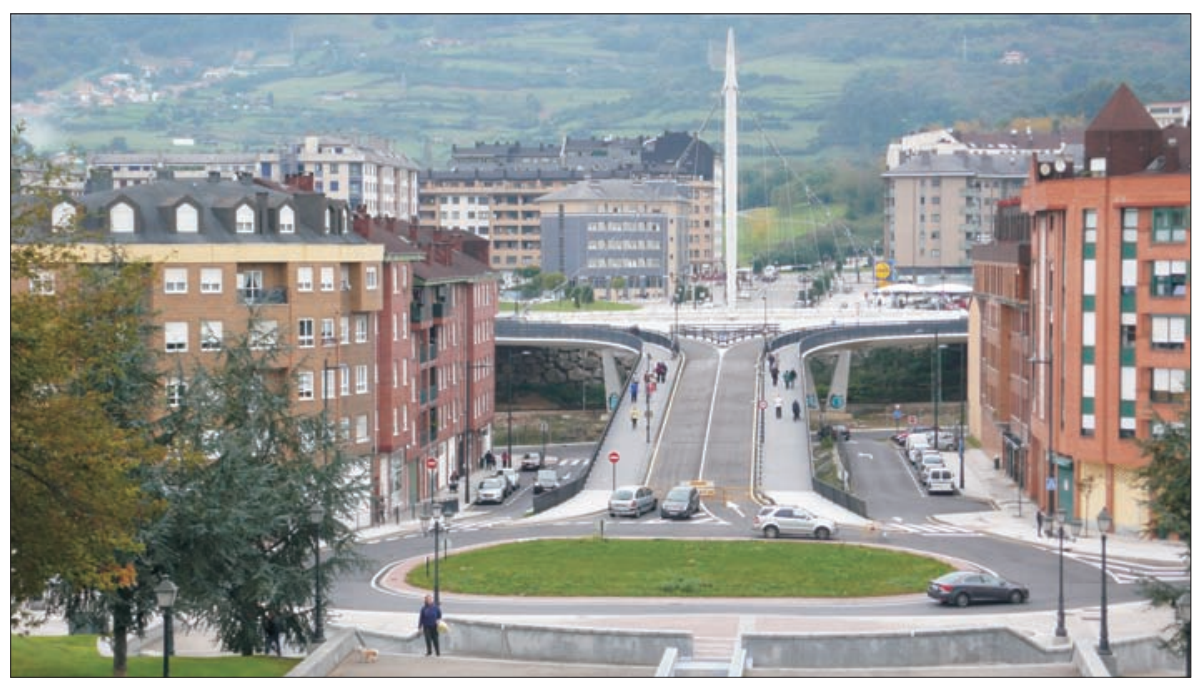

tamiento y Julián Rodríguez ${ }^{25}$ ) serán elementos de peso para abordar su construcción, pues el destino residencial con abundantes equipamientos públicos y un trazado reticular de amplias avenidas, le convertirá en lugar preferente de la mesocracia.

Sin embargo, su puesta en marcha no será inmediata. Los residentes del exiguo reducto urbano no aceptan el sistema de actuación previsto, la cooperación, de modo que de los $431.110 \mathrm{~m}^{2}$ que inicialmente sumaba la superficie del plan parcial, habrá que restar el espacio correspondiente para una nueva unidad de gestión, la ug 2-45, en la que se organizarán aquéllos. Naturalmente, tales cuestiones, así como la búsqueda de nuevas alternativas, retrasan el proceso, que se reinicia en 1994 con la constitución de una junta de promotores, postergándose la urbanización del polígono hasta el año 2000. El cambio de siglo parece originar los movimientos económicos necesarios que darán lugar al desarrollo del nuevo barrio, cuya composición es debida a una estructura viaria sensiblemente ortogonal en la que cobra protagonismo el gran bulevar central de $50 \mathrm{~m}$ de sección. Su desarrollo longitudinal se ve interrumpido por tres glorietas que se acercan a los $100 \mathrm{~m}$ de diámetro, conectadas por un paseo central ordenado con arboleda y flanqueado por dos aceras que

\footnotetext{
${ }^{25}$ Mediante ese convenio, el propietario cede $214.000 \mathrm{~m}^{2}$ de suelo no urbanizable en Monte Alto para ser destinado a parque público recibiendo, en compensación, la posibilidad de destinar $25.400 \mathrm{~m}^{2}$ colindantes a aquél, a vivienda unifamiliar y casi 500 millones de pesetas, de los que aproximadamente la mitad (246.869,370 pesetas) por acuerdo de la Comisión de Gobierno del Ayuntamiento (14-2-1995) se le retribuyen en terrenos de Monte Cerrau. Expediente núm. 1199880242. Sección de Urbanismo. Ayuntamiento de Oviedo.
}

rememoran los largos pasillos verdes del planeamiento desarrollista. Paralelamente a ese gran eje director discurren otros tres, dos de ellos en dirección al trazado del ferrocarril Oviedo-Trubia, de los cuales el más próximo a la trinchera sirve de límite a partir del cual se localizan las superficies comerciales (Lidl, Familia, Repsol), deportivas, (Florida Arena), religiosas (la iglesia de San Antonio de Padua, que sustituye la función educativa inicialmente propuest ${ }^{26}$ ) y parques y jardines públicos. La otra, ceñida a la falda del monte Naranco, da acomodo a dotaciones sociales y espacios verdes.

La previsión de otro gran vial de $35 \mathrm{~m}$ que ensamble el parque de Monte Alto con el del Oeste pone de manifiesto la dimensión que cobran los espacios destinados a parques y jardines, con lo que ello supone de mayor calidad ambiental y disfrute público, pero igualmente de importante aliciente para la promoción inmobiliaria de calidad.

Sobre la planta descrita se construyen cerca de tres mil viviendas (2.844), cuya organización seguirá el esquema de manzanas cerradas rectangulares con espacios libres en el interior de las mismas, modelo que permite

\footnotetext{
${ }^{26}$ La iglesia de San Antonio de Padua estaba en el bajo del número 140 de la calle Argañosa, próxima al entronque de ésta con Bernardo Casielles, y a escasos metros de la hornacina del santo homónimo que aún se conserva en el número 130 y que singularizó ese sector del barrio. Lo inapropiado del lugar de culto, al igual que sucedió con la parroquia de San Melchor, situada inicialmente en otro bajo de la calle Antonio Maura (Vallobín), animaron a feligreses y poder religioso a pedir su traslado a terrenos de La Florida. Aunque la función religiosa se menciona como posible en el documento relativo al Plan Parcial (p. 19) no se le asigna lugar alguno en el plano de usos, en el que, sin embargo, aparece claramente especificado el suelo destinado a equipamientos docentes, uno de los cuales será sustituido por la iglesia y casa rectoral de San Antonio.
} 


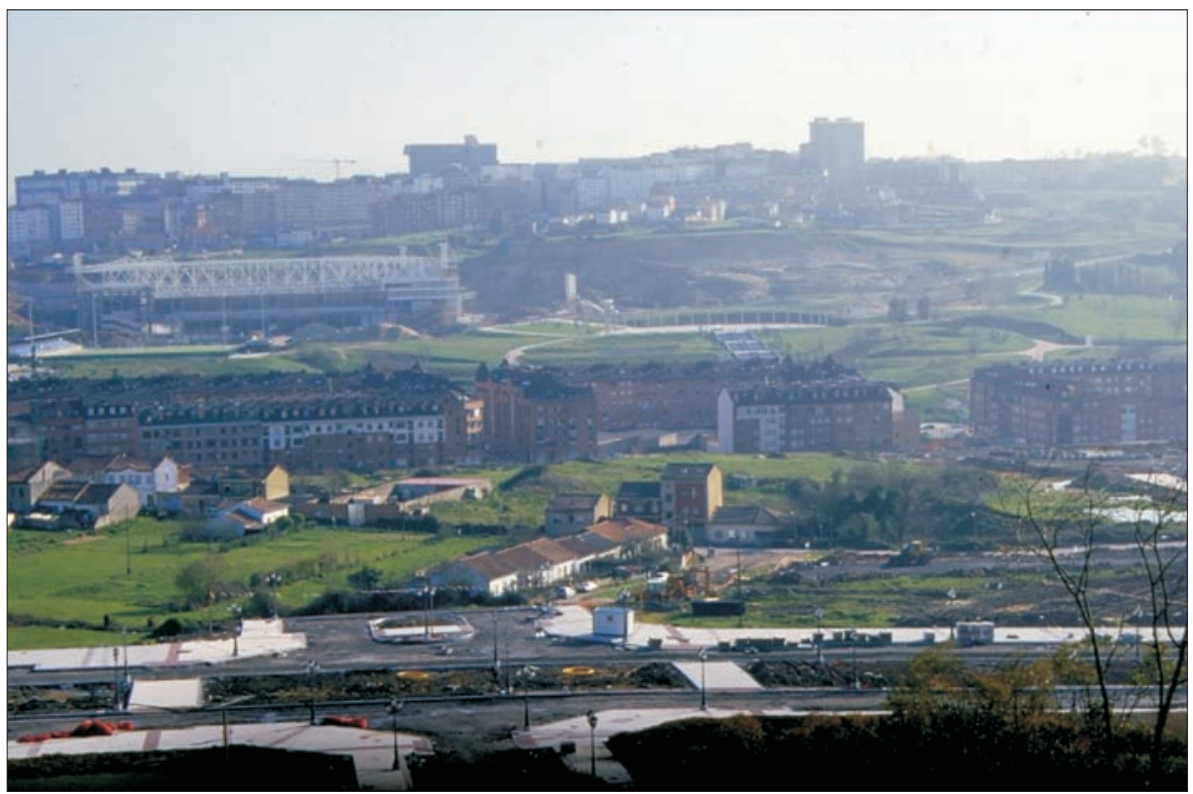

FIG. 12. Las obras de urbanización del Plan Parcial de La Florida en el año 2000 permiten apreciar el caserío preexistente, que dará lugar a la UG 2-45. En segundo plano, y tras la urbanización Pórticos I, puede apreciarse el nuevo estadio de futbol y el parque del Oeste, con el escarpe de la antigua cantera aún visible. Fotografía: $\mathrm{M}$. Madera. distintas modalidades para la expansión privada de los vecinos (piscinas, juegos infantiles, instalaciones deportivas, jardines...), que, naturalmente, confieren elementos cualitativos diferenciadores al nuevo espacio urbano, encontrándose en proporción minoritaria los interiores de manzana con uso y dominio público.

La altura de la edificación se establece en relación al soleamiento y la jerarquía de las calles, así las manzanas que presentan fachada al bulevar tienen ocho plantas y las posteriores seis, escalonamiento que se resuelve utilizando la reducción de los chaflanes traseros a siete alturas como alternativa de transición.

El remate de los equipamientos lo puso el Plan E, pues en noviembre de 2008 el Gobierno socialista de Rodríguez Zapatero aprobó la creación del Fondo de Inversión Municipal para la realización de actuaciones urgentes especialmente generadoras de empleo. El fondo, dotado con 8.000 millones de euros, se inspiraba en la propuesta del FMI durante la cumbre del G-20 en Washington, de destinar 1,2 billones de dólares (el $2 \%$ del PIB mundial) para reactivar la economía mediante la inyección de dinero público (Solbes, 2013). Los ayuntamientos definían los proyectos incluidos en esa financiación extraordinaria, aunque la exigüidad de los plazos para presentar opciones suscitó una frecuente improvisación, dando lugar a dotaciones innecesarias e insostenibles. Con esos fondos se construye la escuela infantil, el único equipamiento docente de los diseñados en el plan, sobre una parcela que combina actividades deportivas (canchas cubiertas de balonmano, baloncesto, futbito y tenis); también el polideportivo Florida Arena, del arquitecto Pérez Arroyo, autor del talud de La Ería, otro proyecto financiado de igual modo. Sin embargo, no se han llegado a construir centros de enseñanza primaria y secundaria, debido en parte a la proliferación en sus inmediaciones de colegios concertados (Teresianas, Ursulinas, Maristas y Nazaret) y públicos (Parque Infantil del Naranco y CP La Ería), que, sin duda, contribuyeron a minimizar una ausencia que ahora se hace patente.

Los avances recientes más reseñables tienen que ver con la mejora en sus conexiones: hacia el oeste, con la prolongación del bulevar hasta Las Campas (mayo de 2012) y con el parque del Oeste a través del puente atirantado, apto para el paso de vehículos y peatones, que vuela sobre el trazado ferroviario de Feve y la carretera de San Claudio hasta la calle Martínez Cachero ${ }^{27}$, finalizado en noviembre de 2015 .

\section{LA UG $2-45$}

Uno de los reproches mas habituales al plan de 1986 es la proliferación de unidades de gestión de dimensiones

${ }^{27}$ El ingeniero Juan José Arenas, autor del proyecto, lo es también del puente de la Barqueta en Sevilla y del puente móvil del puerto de Barcelona. La obra se adjudica a la empresa Assignia Infraestructuras por un presupuesto estimado de cinco millones de euros (La Nueva España, 8-4-2011, 29-12-2012 y 19-5-2013). 


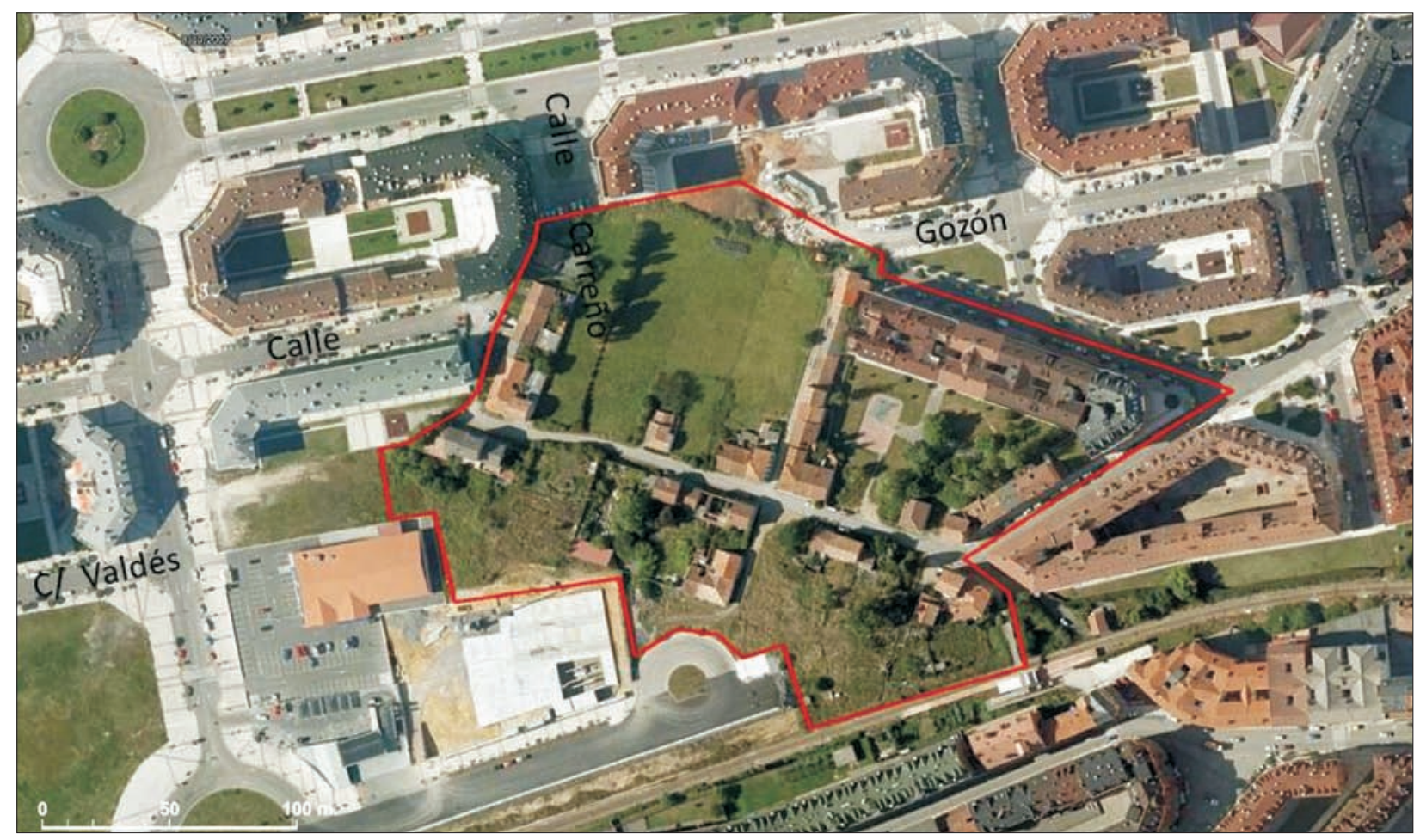

FIg. 13. La unidad de gestión de los Reyes ha supuesto la alteración del proceso constructivo del plan parcial de La Florida. En la imagen de 2007, las calles Gozón, Carreño y Valdés se encontraban interrumpidas dentro de los límites de la ug 2-45. En la actualidad, la primera ya se ha abierto y la segunda se halla trazada. Fuente: Google Earth.

reducidas, por considerar esas actuaciones contrarias a la capacidad global e integradora que caracteriza al planeamiento general. Sin embargo, es ahí donde reside su carácter práctico (Tomé, 2001), al proponer intervenciones viables y adaptables a las circunstancias socioeconómicas mudables, pero también al tratar de ajustar la gestión urbanística a realidades legales, en un intento de dar solución a problemas enquistados que impedían la correcta vertebración de la trama urbana. Aunar voluntades e intereses que suprimiesen obstáculos al desarrollo del modelo proyectado constituía un imperativo ético, pues de lo contrario no podrían racionalizarse ni optimizarse los intereses públicos.

Si la relativa ausencia de edificación en la superficie a urbanizar ${ }^{28}$ facilitó el entendimiento de los propietarios

${ }^{28}$ El ámbito del plan parcial abarcaba 59 parcelas pertenecientes a 48 propietarios, algunas de ellas de titularidad pública, la Consejería de Sanidad que cuenta con casi $18.000 \mathrm{~m}^{2}$ y el Ayuntamiento de Oviedo con poco mas de $10.000 \mathrm{~m}^{2}$, y dos constructoras: Los Álamos con $10.500 \mathrm{~m}^{2}$ y Fercavia, que se aproxima a los $70.000 \mathrm{~m}^{2}$. Renfe dispone de $5.500 \mathrm{~m}^{2}$, pero el mayor propietario es Melquiades Cabal Estrada, a quien, según el Catastro, pertenecen $114.000 \mathrm{~m}^{2}$. para formar una junta de promotores que llevase a cabo la ejecución del plan parcial ${ }^{29}$, la existencia de algunas viviendas preexistentes no dejaba de suponer un obstáculo al avance de la urbanización de La Florida. Para evitarlo, se decide incluir al primitivo enclave en una unidad de gestión, la ug 2-45, popularmente conocida como unidad de gestión de Los Reyes, pues sus calles llevaban los nombres de algunos reyes de la monarquía asturiana. Naturalmente, su ordenación está supeditada a la malla urbana impuesta por el plan parcial, de modo que lo que hoy constituye un desgarro incomprensible en su tejido, logre ser restaurado.

Como era previsible, el ritmo constructivo de ambos espacios reclamaba tiempos diferentes; así, tras las negociaciones de los residentes con las empresas constructoras, el posterior abandono de las viviendas, su irremediable deterioro y la postrera e inevitable ocupación

\footnotetext{
Ayuntamiento de Oviedo, documento de la Junta de Promotores (PP núm. 1, La Florida, 1993).

${ }^{29}$ La ejecución del plan se lleva a cabo mediante el sistema de compensación.
} 


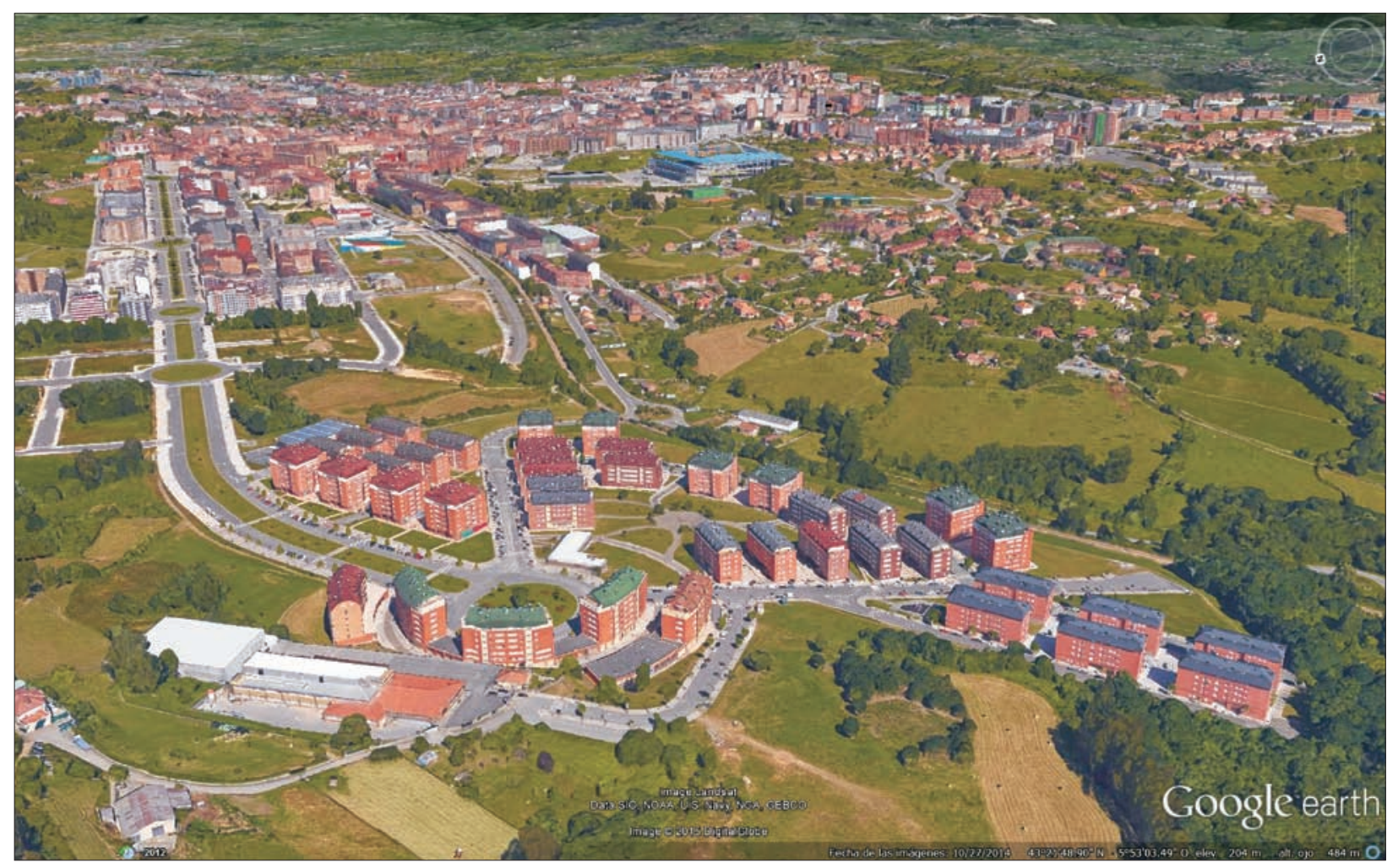

FIG. 14 Las Campas constituye la pieza urbana que sirve de remate al poniente ovetense. La elección de su tipología edificatoria de bloques exentos facilita la transición entre la urbanización difusa de Olivares (a la derecha en segundo plano) y las grandes manzanas de La Florida, espacio a través del cual, tras la apertura en 2012 del último tramo del gran bulevar, se produce su definitivo ensamblaje con la ciudad.

por grupos marginales, aparece el malestar de los nuevos vecinos que advierten la degeneración de ese espacio en sus patios traseros al tiempo que irrumpe un ciclo económico negativo. En esas condiciones se impone el derribo de las ruinas y su posterior vallado perimetral, lo que se produce en 2009; desde entonces la empresa constructora Sedes, propietaria mayoritaria del suelo de ese espacio, ha procedido a la urbanización del $45 \%$ del total, permitiendo la continuidad de la calle Gozón, atrapada en los límites de la Ug hasta 2013.

\section{Las CAMPas}

Las Campas es la pieza que completa el reborde occidental ovetense, una cuña abierta a poniente que supuso la ampliación del radio urbano dando lugar a nuevas formas de paisaje en composición abierta. La reciente apertura (mayo de 2012) de la red arterial que la comunica con la ciudad a través de La Florida culmina un proceso de relativo aislamiento y discontinuidad con el mosaico urbano, al que quizá no sea ajeno el destino de protección oficial de buena parte de sus viviendas.

El ámbito referido se emplaza en la ladera de una pequeña colina de las estribaciones del Naranco, privilegiado y bien orientado balcón desde donde puede abarcarse la contemplación del parque del Oeste, las recientes construcciones de La Ería, el perfil de cuesta de Buenavista y El Cristo y la urbanización difusa en la vertiente de Olivares.

Con la incorporación de España a la Unión Europea se inicia un ciclo alcista en el sector inmobiliario. Al final de la crisis energética le sigue un periodo de confianza determinado por un crecimiento sostenido del PIB que comportó la generación de empleo. El descenso del paro, las facilidades crediticias y las desgravaciones fiscales para la primera residencia van a propiciar un clima favorable a la compra de vivienda por parte de las familias españolas. Tal situación, localmente, supuso modificaciones en el PGOU, pues hubo de transformar el principio de cautela en la previsión de suelo, derivado del aprendizaje del legado urbanístico precedente, para adaptarse 
a una coyuntura de bonanza económica. Ello explica las alteraciones en la clasificación de suelo inspiradas además por la legislación municipal y autonómica de reserva de suelo ${ }^{30}$ destinado, en la proporción fijada, a viviendas con distinto tipo de protección oficial. Éste es el caso que nos ocupa.

Así pues, el plan De la Guardia clasificaba el suelo de Las Campas como «urbanizable no programado» ${ }^{31}$ con la intención de postergar su ordenación a la colmatación previa del crecimiento previsto. Su conversión en «suelo urbanizable programado» para satisfacer las necesidades de vivienda de las clases menos favorecidas requería la modificación del plan general, mediante la creación de un PAU (programa de actuación urbanística) ${ }^{32}$ (López Lucio, 1994) que canalizase el sunP. El Ayuntamiento de Oviedo aprueba en febrero de 1990 las líneas básicas del PAU, cuya superficie afecta a $117.578 \mathrm{~m}^{2}$ destinados a la construcción de 706 viviendas. La necesidad de ser aprobado por la CUOTA o el sistema de ejecución elegido, la compensación, ralentizan el procedimiento, lo que lleva al Principado cinco años más tarde a considerar, de acuerdo a la Reserva de Suelo y Actuación Urbanística Prioritaria (artículo 15, RD 58/94), el dar cauce a las modificaciones de las condiciones incluidas en el PGOU. De modo que ambos instrumentos legislativos se convierten en la base legal que sustenta este cambio, justificado por la necesidad de satisfacer la demanda de un amplio abanico social que no tiene acceso a los altos precios del mercado. La figura elegida para agilizar el proceso es un plan especial y el sistema de ejecución la expropiación; también se incrementa la superficie de la actuación a $184.016 \mathrm{~m}^{2}$, hasta casi duplicar el número de viviendas, pues pasan de 706 a 1.360, de las cuales 225 son de promoción pública (VPO).

El interés en acelerar la puesta en marcha de la operación y la coincidencia de gobiernos del mismo color en Ayuntamiento y Principado motiva la firma de un convenio de colaboración en el que la empresa pública en gestión y promoción de suelo, Gesuosa, como beneficiaria de los derechos expropiatorios del poder local, realiza las

\footnotetext{
${ }^{30}$ Ley autonómica 2/1991, de Reserva de Suelo y Actuaciones Urbanísticas Prioritarias.

${ }^{31}$ El sunP constituyó una de las mayores innovaciones de la ley del Suelo de 1975 que mantuvo el texto refundido de 1992, era una reserva de suelo potencial cuya posibilidad de incorporase al agregado urbano sólo se llevará a efecto cuando la dinámica de desarrollo o aspectos no previstos durante la redacción del PGOU así lo aconsejasen.

32 El PAU es el instrumento capaz de aportar lo que el propio PGOU disponía para el suelo urbanizable programado: desarrollar los sistemas generales, asignarle usos y niveles de intensidad precisando su aprovechamiento medio, trazar las redes de servicios fundamentales y dividir el ámbito de actuación en fases para el desarrollo de las distintas etapas.
}

tareas consistentes en inventariar y realizar la valoración de bienes, sufragar los gastos expropiatorios y urbanizar y vender los solares resultantes. El Plan Especial de Las Campas es aprobado por la CUOTA el 7 de enero de 1997. $\mathrm{Su}$ ordenación subordina su propia estructura a las previsiones del plan parcial limítrofe (La Florida) con el fin de cumplir las determinaciones del PGOU y proyectar una disposición racional del conjunto de la ciudad, de ahí el interés de ensamblar a través del viario las dos piezas urbanas del poniente.

Para sus redactores, la edificación abierta es la solución integradora, pues sirve de transición entre las grandes manzanas de La Florida y la atomización que se advierte al oeste, hacia San Claudio. Esa tipología edificatoria, compuesta por módulos cuadrados y rectangulares, conforma un diseño bien adaptado a la topografía ${ }^{33}$ que culmina en la corona que remata formal y funcionalmente los tres viales estructurantes que confluyen en la glorieta.

\section{FUENTES Y BIBLIOGRAFÍA}

Archivo Municipal del Ayuntamiento de Oviedo: Plan Parcial de Ordenación del Polígono Residencial de La Florida, PP 1, 1969; Memoria. Ejemplar sin encuadernar. Doc.: 17359/23864.

Ayuntamiento de Oviedo (1967): PGOU de Oviedo. Memoria. Ejemplar sin encuadernar.

- (1970): Ordenanzas reguladoras. Plan Parcial de Ordenación del Polígono Residencial de la Florida. Vitrina 3; leg. 22, doc. 6, y publicación del Ayto. de Oviedo, 56 pp.

- (1984) Revisión y adaptación del PGOU del término municipal de Oviedo.

- (1986): Plan General de Ordenación Urbana de Oviedo. Memoria de gestión. Sección de Urbanismo.

- (1986): Documento de Diagnóstico, Objetivos y Ordenación. Documento encuadernado sin paginar. Sección de Urbanismo.

- (1994): Plan Parcial n.o1 La Florida. Junta de promotores. Ejemplar mecanografiado, 61 pp. Sección de Urbanismo.

Documento de Información Urbanística. BOPA, núm. 215. RD 4/86, 12 de junio de 1986.

BorJa, J., y Z. MuXI (eds.) (2004): Urbanismo en el siglo XXI. ETSAB, Barcelona.

\footnotetext{
${ }^{33}$ Las pendientes que ofrece el terreno oscilan entre el $5 \%$ y el $20 \%$; la pendiente media es del $12 \%$.
} 
CARrero de RoA, M. C. (2009): Fundamentos de urbanismo. Una perspectiva sostenible. Ojo x Hoja, Oviedo.

EzQuiaga Domínguez, J. M. (2011): «El planeamiento municipal», en L. Moya (ed.): La práctica del urbanismo. Síntesis, Madrid.

FERnÁndez García, A. (2014): «Los parques de Oviedo y sus relaciones con el patrimonio cultural: riesgos y amenazas». Ería, núm. 94, pp. 207-227.

FonT, A. (2011): «La práctica del planeamiento urbanístico», en L. Moya (ed.): La práctica del urbanismo. Síntesis, Madrid.

Herrán Alonso, M. (2012): El espacio residencial de baja densidad en el municipio de Oviedo. Ediciones de la Universidad de Oviedo, Oviedo.

Leguina, J. (2004): «Que veinte años no es nada», en J. Borja y Z. Muxi (eds.): Urbanismo en el sigo XXI. ET$\mathrm{SAB}$, Barcelona.

LóPEZ DE LuCiO, R.(1994): «Programas de actuación urbanística, planes parciales y proyectos de urbanización», en L. Moya (ed.): La práctica del urbanismo. Síntesis, Madrid.

Madera González, M. (1993): Oviedo, la construcción de la ciudad en el desarrollo económico (1965-1984). Tesis doctoral, Departamento de Geografía, Universidad de Oviedo.

Madera González, M. (2013): «Ciudadanía y ciudad», en Actas del Congreso Ciudadanía y Desarrollo. Instituto de Estudios para la Paz y la Cooperación.

- y S. Tomé (1996): «La operación ferroviaria y urbanística Cinturón Verde de Oviedo». Ería, núm. 39-40, pp. 124-130.
Mesones y Cabello, J. (1967): Plan General de Ordenación Urbana. Memoria.

Montaner, J. M. (2004): «La evolución del modelo Barcelona (1979-2002)», en J. Borja y Z. Muxi (eds.): Urbanismo en el sigo XXI. ETSAB, Barcelona

Pando, L., C. Luque y M. Gutiérrez Claverol (2011): «La cantera de Lavapiés (Cretácico Superior) y su aportación al acervo arquitectónico de Oviedo». Trabajos de Geología, núm. 31.

Quirós Linares, F. (1978): El crecimiento espacial de Oviedo. Universidad de Oviedo, Oviedo.

- (1993): «Oviedo», en Geografía de Asturias. Vol. 3, Salinas, Ayalga, pp. 90-180.

SANZ, O. (1969): «Doce mil viviendas tendrán cabida en el polígono residencial de La Florida». La Nueva España, 30 de noviembre de 1969, pp. 7-9.

Solbes, P. (2013): Recuerdos. Deusto.

TERÁn, F. de (1982): El problema urbano. Salvat, Barcelona.

Tomé Fernández, S. (1988): Oviedo. La formación de la ciudad burguesa, 1850-1950. Colegio Oficial de Arquitectos de Asturias, Oviedo.

- (1992): «La ciudad de Oviedo», en Geografía de Asturias. T. III, Editorial Prensa Asturiana, Oviedo.

- (2001): Oviedo, paisajes urbanos en desaparición. Universidad de Oviedo, Oviedo.

- y G. Morales (2009): «Los espacios verdes en las ciudades y villas de Asturias». Ería, núm. 78-79.

TRAPERo, J. J. (1994): «La práctica del planeamiento urbanístico en España», en L. Moya (ed.): La práctica del urbanismo. Síntesis, Madrid. 